\title{
The Impact of Choice: Exercise Motivation and Physical Activity in College Students Enrolled in Fitness for Life
}

Julia Fera Tracy

Follow this and additional works at: https://researchrepository.wvu.edu/etd

\section{Recommended Citation}

Tracy, Julia Fera, "The Impact of Choice: Exercise Motivation and Physical Activity in College Students Enrolled in Fitness for Life" (2015). Graduate Theses, Dissertations, and Problem Reports. 6825.

https://researchrepository.wvu.edu/etd/6825

This Dissertation is protected by copyright and/or related rights. It has been brought to you by the The Research Repository @ WVU with permission from the rights-holder(s). You are free to use this Dissertation in any way that is permitted by the copyright and related rights legislation that applies to your use. For other uses you must obtain permission from the rights-holder(s) directly, unless additional rights are indicated by a Creative Commons license in the record and/ or on the work itself. This Dissertation has been accepted for inclusion in WVU Graduate Theses, Dissertations, and Problem Reports collection by an authorized administrator of The Research Repository @ WVU.

For more information, please contact researchrepository@mail.wvu.edu. 
The Impact of Choice: Exercise Motivation and Physical Activity in College Students Enrolled in Fitness for Life

Julia Fera Tracy

Dissertation submitted to the College of Physical Activity and Sport Science at West Virginia University in partial fulfillment of the requirements for the degree of Doctor of Education in Physical Education Teacher Education

\author{
Andrea Taliaferro, Ph.D. Chair \\ Robert Wiegand, Ed.D. \\ Valerie Wayda, Ed.D. \\ John Oughton, Ed.D. \\ Alfgeir Kristjansson, Ph.D.
}

Department of Coaching and Teaching Studies

Morgantown, West Virginia

2015

Keywords: Self-determination Theory, Adult Learning Theory, Physical Activity, Autonomy, Higher Education, Motivation

Copyright 2015 


\begin{abstract}
The Impact of Choice: Exercise Motivation and Physical Activity in College Students Enrolled in Fitness for Life

Julia Fera Tracy
\end{abstract}

Background: Research suggests there is a decline in physical activity (PA) as individuals enter adulthood (Sallis, 2000). Physical activity behaviors that students develop during college years are said to have a long-term impact on adult habits (Keating, Guan, Pinero, \& Bridges, 2005). Leslie, Sparling, and Owen (2001) suggest that college campuses are central settings with unseen opportunities to influence young adults' PA patterns. Higher education PA programs can be a mechanism to introduce adults to healthy lifestyles that include PA (Hardin, Andrew, Koo, \& Bemiller, 2009).

Purpose: The purpose of this study was to investigate the impact of choice in a conceptuallybased college health and wellness course on exercise motivation and PA of undergraduate students.

Method: This study employed a mixed method design. Quantitative data from the Behavioral Regulation in Exercise Questionnaire (BREQ-2) and the Leisure Time in Exercise Questionnaire (LTEQ) were collected over three time points. Participants $(N=81)$ experienced instruction that was either autonomously supportive (choice) or controlling (non-choice) in an effort to determine the impact of these approaches on improving levels of PA and motivation. Qualitative data from semi-structured interviews with course instructors $(N=4)$ and open-ended questions were also collected.

Results: There was a significant increase in intrinsic regulation $F(2,158)=10.13, p=.00, \eta_{\mathrm{p}}{ }^{2}$ $=.114$; identified regulation $F(2,158)=7.35, p=.001, \eta_{\mathrm{p}}{ }^{2}=.085$; introjected regulation $F(2$, $158)=6.61, p=.002, \eta_{\mathrm{p}}{ }^{2}=.077$; and PA $F(2,158)=5.63, p=.004, \eta_{p}^{2}=.067$ over time. No significant group differences were found.

Conclusion: While there was no significant difference between instruction type, instructors and participants suggested that choice was the preferred method for adult learners; however, individuals may need initial support with gradual increase in autonomy. Future research is warranted to investigate how increasing autonomy through choice can lead to higher autonomous motivation. 


\section{Dedication}

This work is dedicated to my family, especially my husband, Lloyd, and our children (Lloyd Jr., Emerson, and Corrigan). I am eternally grateful for my husband and his overwhelming support and encouragement. He has heard more about self-determination and adult learning than he probably cares to hear. He has also kept me inspired and helped me through the highs and lows. Thank you and I love you! My children have been extremely patient and understanding throughout this process. You all have kept me grounded and given me the motivation (no pun intended) to persevere. I love and appreciate you more than words can express. 


\section{Acknowledgments}

I would like to thank all my family, friends, and everyone who has helped me in this process. I have bent many ears and am very appreciative.

I would like to thank my committee: Dr. Andrea Taliaferro, Dr. Alfgir Kristjansson, Dr. Robert Wiegand, Dr. Valarie Wayda, and Dr. John Ougton. Dr. T, thank you for your time as my committee chair. I appreciate the additional efforts needed to work with me from a distance. Your guidance and encouragement over the last few years are greatly appreciated. You have been a great friend and mentor.

Thank you to my colleagues at Shepherd: Dr. Stacey Kendig, Dr. Desmond Lawless, Dr. Jared Androzzi, and especially Dr. Rhonda Hovatter. Thank you for your time and efforts helping me through this process. Your listening ears and support were very helpful.

I would also like to thank my parents, Margaret and Francis Fera. I am immensely appreciative of the time you have devoted to helping me throughout this process. Your love, support, and encouragement are immeasurable. I am especially grateful for the time you have put in helping me with my children. I appreciate the many hours spent watching them and getting them to their extracurricular activities for me (sometimes at last minute notice) while I had classes or had to travel to Morgantown. I am extremely appreciative and I love you!

Finally, I would especially like to thank my mother-in-law, Dr. Kay Tracy. She has been a supportive role model and mentor to me throughout this process. She has been my editor, my friend, my listening ear, my confidant, and most of all my inspiration. I cannot express my appreciation enough for your time and devotion to my work. I am eternally grateful. 


\section{Table of Contents}

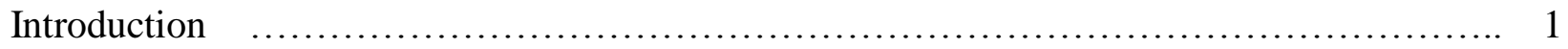

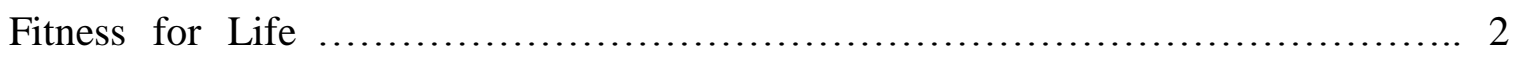

Theoretical Framework .................................................... 4

Self-determination Theory....................................... 4

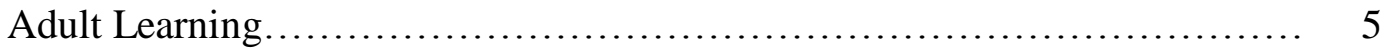

Statement of Purpose................................................ 7

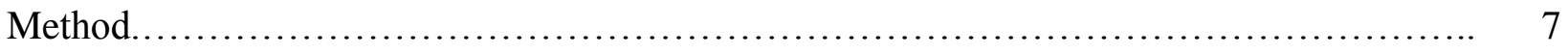

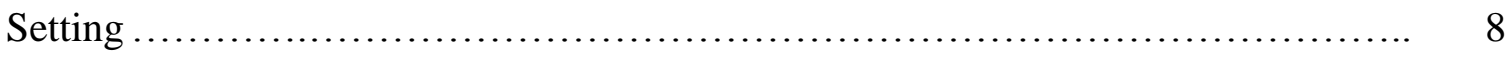

Participants......................................................... 9

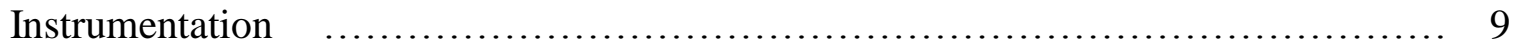



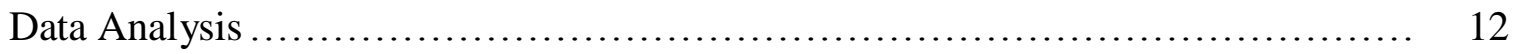

Results and Discussion................................................. 14

Limitations............................................................ 24

Conclusions and Future Research.............................................. 24

References........................................................... 27

Tables and Figures.......................................................... 31

Appendix A Review of Literature ........................................... 43

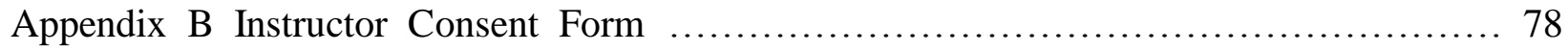

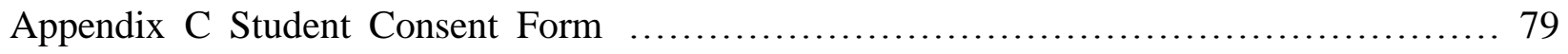

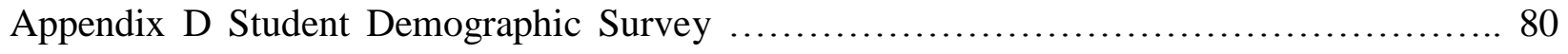

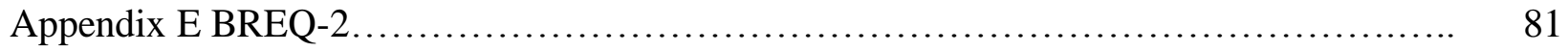




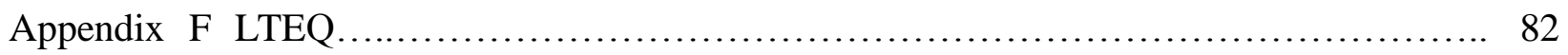

Appendix G Open-ended Questions........................................... 83

Appendix H Semi-structured Interview Questions................................ 84

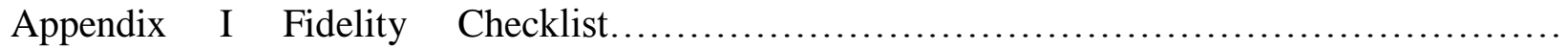

Appendix J Physical Activity Day Workout Template.....

Appendix K Physical Activity Day Non-Choice................................. 88

Appendix L Cover Letter-Student............................................ 89

Appendix M Cover Letter-Instructor............................................ 90 


\section{Introduction}

Research indicates that individuals' physical activity (PA) levels decline as they enter young adulthood (Sallis, 2000). The typical young adult is juggling multiple responsibilities including work, school, and family, which contribute to this decline. According to Medero (2012), colleges are exemplary institutions for principles of healthy living, such as diet and exercise, to be taught. College can be a place to present opportunities and responsibilities that allow campus communities to positively impact PA behaviors in their students (Leslie, Sparling, \& Owen, 2001). Perhaps due to the similarity in contexts, behaviors that students develop during the college years have been found to have a long-term impact on adult habits relating to maintaining PA (Keating, Guan, Pinero, \& Bridges, 2005).

The Healthy Campus 2020 initiative was designed to provide a framework for improving the overall health status on college campuses around the nation (American College Health Association, 2012). According to this initiative, smoking, unhealthy eating habits, and sedentary lifestyles are three major risk factors that can increase the likelihood of developing heart disease, type 2 diabetes, lung disease, and some cancer. Additionally, these four chronic diseases contribute to more than 50 percent of preventable deaths in the world (American College Health Association, 2012). The American Heart Association (2014) reports that 68 percent of all adults are currently considered obese or overweight and these levels continue to increase among adults and children. Increasing PA in college students is one of many student objectives documented by Healthy Campus 2020. College students may be at risk of suffering from health complications later in life if they do not participate in regular sessions of PA and begin to lead healthier lifestyles, both known to combat obesity (Medero, 2012). Therefore, the ability to increase or 
maintain an individual's pattern of PA is a critical component of the health and wellness initiative.

Along these lines, colleges and universities across the country offer health and wellness courses in hopes of influencing students to maintain or improve their current levels of fitness. However, relatively little research has been conducted on the effectiveness of these courses in increasing or maintaining motivation and lifetime PA patterns. Pearman (1995), for example, evaluated the implications of a required college health and physical education class by examining the health status of almost 2,000 alumni. Survey results concluded that completion of the required college physical education class had a positive effect on self-reported health-related knowledge, attitudes, and behavior of alumni who participated in these courses. Student health habits also were positively influenced by participation in the college physical education class, with significantly more of the participants surveyed indicating that they continued to practice positive health habits such as running and jogging. Additionally, Medero (2012) concluded that there was a significant positive relationship between enrollment in a university health and wellness course and improvement of cardiorespiratory endurance, muscular endurance, and strength. Participants who were enrolled in the university health and wellness course also gained knowledge on health-related topics, and reported an increase in their desire to participate in PA and exercise self-efficacy at the completion of the course. Thus, it appears that the additional experience of a required college physical education class can greatly enhance one's healthrelated knowledge and behaviors well beyond norms (Pearman, 1995).

\section{Fitness for Life}

Smaller institutions (less than 5000 students) tend to offer a more holistic health and wellness approach to their physical education requirement (Lumpkin, 1993). This 
multidimensional, concept-based class, sometimes referred to as Fitness for Life, is frequently a requirement in smaller institutions (Hensley, 2000; Leslie, et al. 2001). The Fitness for Life conceptual framework is thought to have emerged from the increasing attention to health and fitness in America over the past 10-15 years (Hensley, 2000). Fitness for Life courses are designed to incorporate in-class lectures and out-of-class PA, with the goal being to combine knowledge with favorable experiences of engaging in PA. The Fitness for Life approach is used in approximately 52 percent of colleges and universities that have a physical education requirement for general college students (Leslie et al., 2001). Leslie et al. (2001) also indicated that 60 percent of all institutions offer the multidimensional, concept-based course most often referred to as Fitness for Life, whether required or not.

While research suggests that college courses contribute to significant health benefits (Alemeda, 2009), there is limited research on the impact of motivation towards PA among college students (Keating et al. 2005). Leslie et al. (2001) suggested that young adults are a dismissed population, but an important group to target for PA interventions, and that campuses are central settings with unseen opportunities to influence young adults' PA patterns. An improved understanding of college students' motives for engaging in PA would assist in the advancement of tailored interventions in health and wellness courses, such as strategies to increase participation in PA, aiding in improved health-related fitness and overall health (Kilpatrick, Hebert, \& Bartholomew, 2005). Self-determination theory is instrumental in helping to recognize not only why students engage in PA, but also in determining whether they will continue to exercise over the long-term (DeLong, 2006). 


\section{Theoretical Framework}

\section{Self-Determination Theory}

Motivation plays a significant role in the success of upholding health and wellness goals. According to Ryan, Kuhl, and Deci (1997), self-determination theory is an approach to human motivation that focuses on humans' inner resources for behavioral regulation. It is rooted in early motivation theory, based on the driving forces of physiological and psychological needs such as competency, autonomy, and relatedness (Ryan \& Deci, 2000). In addition, self-determination theory ascertains that humans are active organisms motivated toward growing, mastering challenges, and integrating new experiences into their sense of self (Ryan \& Deci, 2000).

According to self-determination theory, motivation can be intrinsic, extrinsic, or nonexistent, i.e. amotivation (Sibley, Hancock, \& Bergman, 2013). Fluctuating levels of selfdetermination influence the selection of actions that present desired motivational outcomes (Standage, Duda, \& Ntoumanis, 2003). Ryan and Deci (2008) suggest that there are two different types of motivation: autonomous and controlled. Autonomous motivation consists of both intrinsic and extrinsic motivation and can inspire greater long-term persistence, such as maintaining a physically active lifestyle (Ryan \& Deci, 2008). Motivation affecting PA is likely to be more robust if it involves greater choice and self-determination rather than external control (Pethkar, Naik, \& Sonawane, 2010).

The current literature universally supports a positive relationship between teachers' classroom autonomy support and students' educational outcomes (Reeve, Jang, Carrell, Jeon, \& Barch, 2004). Autonomy-supportive teachers enable self-determined motivation in students by creating an environment that nurtures student needs, interests, and preferences (Reeve et al., 2004). For example, a study by Standage et al. (2003) on children's motivation in secondary 
school physical education classes concluded that physical education teachers should employ alternative strategies that are autonomy-supportive and mastery-focused, which ultimately facilitates self-determined motivation. Thus, exercise leaders should make an effort to enhance participants' feeling of autonomy (control and volition) to develop more autonomous types of exercise motivation. Reeve et al. (2004) suggested future research exploring the possibility that autonomy-supportive teaching (i.e., offering more freedom of activity choice) in a physical education setting may increase engagement in PA as well as motivation.

In a study of 194 college students that aimed to identify the relationship between exercise motives, exercise behavioral regulation, and physical fitness, Sibley et al. (2013) concluded that additional autonomous forms of exercise are related to more adaptive exercise behaviors; therefore, leaders should encourage autonomous motives in these individuals in order to sustain their exercise engagement. Positive associations between certain types of motivation and fitness would indicate which motivations (e.g. extrinsic or intrinsic in nature) should be encouraged in university PA settings (Sibley et al., 2013). Similarly, Brunet and Sabiston (2011) investigated motivation and PA patterns in adults $(N=547)$, and found that as young adults' PA levels increase, so too do their beliefs and values regarding PA. Thus, it would be beneficial for PA interventions to help encourage and sustain autonomous regulations within young adult populations.

\section{Adult Learning Theory}

Knowles' (2011) Adult Learning Theory highlights the characteristics of adult learners and how they differ from school-aged learners. The self-concept of the adult learner suggests the need and ability for autonomy and self-directed learning. In addition, adult learners value relevancy and the connection of life experiences to class material (Young, 2012). Moreover, 
adults prefer learning that is strongly under their own control, applicable to their own lives, and embodied in active concrete experiences (Westbrook, 2005). Knowles (1977) suggested that the true andragogue (teacher of adults) has a built-in obligation to help the learner move from dependency toward increasing self-directedness.

These characteristics of adult learners, combined with the knowledge of motivational and behavioral effects, give rise to this inquiry into the impact of choice within a college Fitness for Life class. Knowles' andragogical model suggested that the self-concept of the adult learner drives the need for autonomy. Past research has suggested that autonomy positively correlates to the learning process and motivation, but these studies have focused on high school physical education students as subjects or where conducted in the classroom setting (Hagger, Chatzisarantis, Culverhouse, \& Biddle, 2003; Reeve et al., 2004). To date, there has been limited research on andragogical teaching strategies applied in the adult college physical education setting.

Since adults have the ability to be autonomous and self-directed in their learning, allowing more control in the choice of PA during the Fitness for Life class may increase their overall exercise motivation. Additionally, it is known that autonomous motivation leads to greater persistence in a behavior (Sibley et al. 2013). Ryan and Deci (2007) suggest that if individuals do not enjoy the activity or discover its inherent satisfactions, they are not likely to persist in it. The concept of autonomy that is central within self-determination theory has long been recognized as a fundamental factor in the promotion of optimal motivation. Additionally, autonomy and the need to be more self-directed in the learning process are central components in Adult Learning Theory. Combining Adult Learning and Self-Determination theories, it can be 
hypothesized that allowing adults to choose PA during Fitness for Life classes may improve exercise motivation as well as PA levels.

\section{Statement of Purpose}

The purpose of the current study was to investigate the impact of choice in a conceptually-based college health and wellness course, Fitness for Life, on exercise motivation and PA of undergraduate students. Participants, who have self-selected into one of two distinctly different courses, experienced instruction that was either autonomously supportive (choice) or instruction that was controlling (non-choice) in an effort to determine the impact of these approaches on improving levels of PA and motivation (intrinsic, identified, introjected, external, amotivation). Additionally, students' and instructors' descriptions of their experiences in choice versus non-choice were explored.

\section{Method}

This study employed a sequential explanatory mixed methods design to investigate the impact of choice on exercise motivation and PA, depicted as Quan $\rightarrow$ qual. The purpose of this design was to use qualitative results to aid in explaining and interpreting the findings of a primarily quantitative study (Clark \& Creswell 2008). Additionally, the instructors of the college health and wellness courses participated in a semi-structured interview session at the conclusion of the course. A framework analysis approach (Gale, Heath, Cameron, Rashid, \& Redwood, 2013) was used to analyze the interview data in order to further interpret and support the findings of the study. This study was approved by the University Institutional Review Board.

\section{Setting}

Course description. This study was conducted at a four-year liberal arts university located in the Eastern Panhandle of West Virginia. The course in focus, Fitness for Life, is a 
three-credit conceptually-based health and wellness course that includes lecture/laboratory approach with a PA component. This is one of two options from which student participants can choose in order to complete the university's wellness core curriculum requirement for graduation. The PA and laboratory sessions included in the course allow for practical application of concepts with the goal of establishing a pattern for a lifetime of fitness and wellness, as well as an appreciation of the enjoyment of physical exercise. All instructors for Fitness for Life courses follow specific guidelines outlined by the University Fitness for Life chairperson which determine content and structure. In the typical course structure, students participate in a PA session on a weekly basis throughout the 15 -week semester.

Choice of activity. During the weekly PA day, students in the choice curriculum class sections were given the opportunity to select the type of activity in which they would engage. Inclass lecture material covered areas such as the components of fitness, principles of training, and components of an appropriate workout session. In order to reinforce accountability, students turned in workout sheets (as part of the class requirements) which outlined the particular activities in which they engaged in on each class day (See Appendix J).

Non-choice of activity. During the weekly activity day, students in the non-choice groups participated in a PA session which was planned and implemented by the instructor. The instructor determined all aspects of the activity in which the students engaged with little to no student choice. Examples of instructor-led activities consisted of team sport activities (e.g., table tennis and racquetball, group exercises, and organized game activities). Additionally, one instructor set up workout programs for students to complete in the university wellness center. 


\section{Participants}

Instructors. Four instructors teaching Fitness for Life at the University in focus were recruited and agreed to take part in the study. Two instructors employed the choice method during the PA portion of this course and two employed the non-choice approach. Three instructors held a terminal degree and had approximately five years of experience teaching in higher education. The fourth instructor held a master's degree with seven years of teaching and coaching experience in higher education.

Students. Participants in this study were 81 college students ( $n=37$ female, 44 male) enrolled in four different sections of Fitness for Life. Undergraduate student participants were recruited from the classes in which instructors had been established for the study. The primary researcher recruited from 4 sections ( 2 choice and 2 non-choice) which initially resulted in a purposeful sample of approximately 87 students. Students self-selected into each section of fitness for life which naturally formed groups. Participants included 52 freshman (60.5\%), 11 sophomores (12.3\%), 17 juniors (21\%), and 6 seniors (6.2\%), with a mean age of 19 (range $=17$ - 31). The participants included 60 athletes and 26 non-athletes.

\section{Instrumentation}

Behavioral Regulation in Exercise Questionnaire. The revised Behavioral Regulation in Exercise Questionnaire (BREQ-2) was used to measure motivation (see Appendix D; Markland, \& Tobin, 2004). The BREQ-2 measures 5 subscales of exercise motivation: external regulation (4 items, e.g., "I exercise because other people say I should"); introjected regulation (3 items, e.g., "I feel guilty when I don't exercise"); identified regulation (3 items, e.g., "I value the benefits of exercise"); intrinsic regulation (4 items, e.g., "I exercise because it's fun"); and amotivation (4 items, e.g. "I don't see why I should have to exercise"; Markland \& Tobin, 2004). 
Scores for each of the subscales of the BREQ-2 range from $0-4$, with 0 indicating a low score and 4 indicating a high score.

A confirmatory factor analysis by Markland and Tobin (2004) indicated an excellent fit to data (Satorra-Bentler Scaled Chi Sq $=136.49, d f=125, p=.23 ; \mathrm{CFI}=.95$; RMSEA = .02, $90 \% \mathrm{CI}=.00-.04 ; \mathrm{SRMR}=.05)$, with Chronbach's alpha reliabilities for each subscale ranging from .73-.86. Items within each subscale were averaged, resulting in one score per participant per subscale.

The Godin-Shephard Leisure-Time Physical Activity Questionnaire. The GodinShephard Leisure-Time Physical Activity Questionnaire (LTEQ), which can be found in Appendix E, was used to measure PA (Godin, 2011). The LTEQ is a three-item questionnaire which allows the assessment of self-reported leisure-time PA. Participants are asked to recall on average the number of times per week they engage in at least fifteen minutes of strenuous, moderate, or mild exercise. According to Godin (2011), numbers given for each category of effort are multiplied by $(9 \times$ strenuous, $5 \times$ moderate, and $3 \times$ mild $)$ and this results in a MET (Metabolic Equivalent of Task) value for the week. The validity of the LTEQ to assess leisure time PA has been confirmed through multiple studies (Godin, 2011; Godin \& Shephard, 1985). Additionally, studies have shown acceptable reliability in assessing exercise behavior (Markland, 2009).

Demographics survey. The demographics survey (see Appendix C) is a 7-item researcher-developed questionnaire that includes items such as gender, GPA, level in college, and current level of PA. The questionnaire helped the researcher define the population being studied. 
Open-ended questions. During time-point three, student participants were asked to answer four open-ended questions designed to help interpret findings from the survey results (see Appendix G). Participants were asked about their perceptions of, and were asked to describe their experiences in, choice or non-choice.

Semi-structured interview guide. The interview guide for the semi-structured interviews (see Appendix H) was designed by the primary researcher to gain a better understanding of the implementation of choice or non-choice from the instructor's perspective. The interview guide contained questions focusing on instructor experiences and perceptions of the impact of choice or non-choice on student motivation and PA, as well as barriers and/or challenges to implementing this teaching style.

Fidelity check instrument. The fidelity check was a 6-item checklist that the researcher developed and used to ensure instructors were teaching using the style in which they were recruited to teach (see Appendix H). Items on the checklist consisted of statements that describe what is taking place or being observed during the PA day in order to differentiate between the two teaching styles.

\section{Data Collection Procedures}

Survey data. The primary researcher recruited participants by visiting four pre-selected Fitness for Life classes (two for each instructor). The primary researcher visited these classes during three selected times throughout the semester; Time 1 (week 1), Time 2 (week 8), and Time 3 (week 15). On Time 1, participants who agreed to participate and signed the informed consent form completed the demographics survey, BREQ-2, and the LTEQ. Students who were not enrolled in the class on day 1 but who "added" this course within the drop/add period were given the opportunity to enter the study at that time. 
In weeks 8 and 15 of the semester, participants again completed the BREQ-2 and LTEQ during class time. During Time 3 (week 15), the survey also contained the 4 open-ended questions described above. If a student was absent during data collection at either Time 2 or 3 , the course instructor followed up with the student and provided them with an opportunity to complete the surveys at the next class meeting.

Fidelity checks. Prior to the start of the study, instructors were provided instructions and guidelines from the primary researcher on how to employ both choice and non-choice teaching strategies. Instructor fidelity checks occurred within the first two weeks of the semester, as well as two more times throughout the semester, to ensure instructors were teaching according to the assigned strategy. The primary researcher made three unannounced visits to observe each of the instructor's Fitness for Life classes and used the fidelity checklist to help determine the instructors' method of teaching (see Appendix I). Fidelity checks concluded that all instructors were meeting the expectations set by the primary researcher in terms of teaching styles employed.

Semi-structured interviews. At the end of the semester (week 15), the instructors in both the choice and non-choice groups $(n=4)$ participated in a semi-structured interview session, which was designed to gain a better understanding of instructor perceptions and add to the body of knowledge on the impact of choice on motivation and PA (see Appendix H). Instructors signed an informed consent form prior to questioning (see Appendix B). The sessions lasted approximately 30 minutes and the interviews were audio-recorded.

\section{Data Analysis}

Data from the demographics survey was entered into an Excel file and descriptive statistics were calculated. Scores from the BREQ-2 and LTEQ were calculated, entered into 
SPSS, and analyzed to determine missing data. Descriptive statistics and alpha confidents were gathered on all measures.

Of the eighty-seven students enrolled in the four pre-selected sections of Fitness for Life, eighty-six agreed to participate. There were five participants from the initial eighty-six who dropped the course and subsequently were dropped from the study. There were ten participants who missed one round of data collection. The missing data was replaced with mean scores. This option was chosen to be optimal based on the small amount of missing data and is said to be the most straightforward method (Norman \& Streiner, 2008).

Group differences at baseline. Pearson Chi-square tests were run on gender, year in school, student athlete status, and reason for registration for each group (choice/non-choice).

Differences in motivation and PA over time. Mean scores from questions pertaining to each of the five subscales of motivation on the BREQ-2 and LTEQ scores were calculated. Six separate two-way repeated measures analysis of variance (ANOVA) with Bonferroni correction (Stevens, 2009) were run on each of the subscales of the BREQ-2. The Bonferroni correction set the $p$ value at .01. Additionally, a two-way repeated measures ANOVA was run on the scores from the LTEQ.

Participant perceptions of choice and non-choice. Responses from the open-ended questions were transcribed into chart form; the data collected from the open-ended questions was reviewed and categorized by the researcher in order to determine how students described their experiences in choice versus non-choice teaching styles. Each response was coded based on patterns in the responses. Each code was then categorized by common themes that emerged. Incorporating accounts from the respondents helped further explain and support why differences in motivation occurred and were reported in descriptive text. 
Instructor perceptions of choice and non-choice. Audio files from the semi-structured interviews were transcribed verbatim. A "framework analysis" approach was used during this part of data analysis, which involves familiarization, identifying a thematic framework, indexing, charting, mapping and interpretation of data. The Framework Method is most commonly used for the thematic analysis of semi-structured interview transcripts (Gale et al., 2013).

Familiarization with the data transcription is a beginning step in the data analysis process and a vital stage in interpretation of the data. Following familiarization with the data, "open coding" took place. Open coding is an inductive approach which allows codes to be defined as themes develop (Gale et al., 2013). The final step in the qualitative data analysis process involved charting the codes into a working matrix that was ultimately used to aid in drawing descriptive and/or explanatory conclusions associated around themes.

\section{Results and Discussion}

Cronbach's alpha coefficients were run on the subscales of the BREQ-2 to test for internal consistency (see Table 1). Additionally, chi-square tests and t-tests were run to test for group differences (See Tables $2 \& 3$ ). Results indicated that there were no group differences at baseline.

\section{Differences in Motivation Over Time and Between Choice and Non-choice Groups}

A two-way repeated measures analysis of variance (ANOVA) was conducted on each of the subscales of motivation and PA (BREQ-2 and LTEQ) to evaluate the change in motivation for each subscale (see Table 4).

External. An individual is externally regulated when, for example, they exercise because someone tells them they should or they feel pressure from outside sources (i.e. family and friends) to exercise. The results of a 2-way ANOVA indicated no significant effect for extrinsic 
motivation over time, $F(2,158)=1.98, p=.14, \eta_{\mathrm{p}}{ }^{2}=.024$. Additionally there were no significant differences between groups, $F(2,158)=.24, p=.78, \eta_{\mathrm{p}}{ }^{2}=.003$.

External regulation refers to actions controlled by contingencies external to the individual like rewards or punishment (Deci and Ryan, 1985). Overall external regulation scores were low with mean scores ranging from $.58-.89$. While there were no significant differences over time or between groups reported, the non-choice external regulation mean scores were slightly higher in each round (see Table 5). This could be due to the fact that the instructor in the non-choice class was leading the activity, which is consistent with an individual exercising because someone else tells them to. Controlling environments result in individuals feeling less autonomous and selfdirected. This level of regulation is not consistent with an individual continuing to engage in PA over time or remain persistent in that level of PA (Ryan \& Deci, 2008).

Intrinsic. Intrinsic regulation is the highest level of self-determination and suggests that individuals exercise because they enjoy it and feel pleasure and satisfaction from exercising. Results of a two-way ANOVA revealed a significant effect over time for intrinsic motivation, $F(2,158)=10.13, p=.00, \eta_{\mathrm{p}}{ }^{2}=.114$ with no significant difference between groups, $F(2,158)=$ $.42, p=.65, \eta_{\mathrm{p}}{ }^{2}=.005$. Mean scores increased from 2.7 to 3.04 over time.

Intrinsic regulation significantly increased over time for both groups; however, mean scores between groups were very similar (see Table 3). The possibility that an individual was able to find inherent satisfaction in the PA in which they engaged in during the semester could explain the increase in intrinsic motivation. It would appear that the class itself and experiences in both choice and non-choice styles were effective at increasing intrinsic motivation, and no one experience had a greater impact on intrinsic motivation. Part of the Fitness for Life curriculum educates students on goal setting. Students in the course are encouraged to set goals and develop 
plans for behavior change. Ryan and Deci (2008) suggest that individuals who are autonomously motivated (which encompasses intrinsic motivation) experience a self-endorsement for their actions. This self-endorsement could be a result of goal reflection and adoption, and therefore may have contributed to the increase in motivation among both groups.

Identified. Identified regulation suggests that an individual exercises because they value the benefits that result from exercise (i.e., health benefits). Results of a 2-way ANOVA indicated a significant effect over time for identified motivation, $F(2,158)=7.35, p=.001, \eta_{\mathrm{p}}{ }^{2}=.085$ with no significant difference between groups, $F(2,158)=1.03, p=.35, \eta_{\mathrm{p}}{ }^{2}=.013$. Overall mean scores significantly increased from 2.8 to 3.09 over time.

While identified regulation is considered a type of extrinsic motivation, it has a very high degree of self-regulation as opposed to external regulation, which has a very low degree of selfregulation (Ryan \& Deci, 2000, 2008). Results indicate that both groups increased in identified regulation from Time 1 to Time 3 (see Figure 2). One objective of the Fitness for Life course is to inform students about the health-related benefits associated with PA. Additionally, students typically learn about goal setting and how to develop personalized exercise programs. This could explain the increase in identified regulation because the activities performed, whether through freedom of choice or instructor directed, could associate with the participants' personal goals developed during the course.

The personality of the instructor or the participant could have been a factor in the lack of a significant difference in identified regulation between groups. Although the fidelity checklist ensured each teaching style was being implemented, the lack of differences between these two groups could suggest that students did not necessarily perceive one type of climate (teaching 
style) over the other. Additionally, the course itself may have had a larger impact on participants than did their freedom of choice in activities.

Introjected. Introjected regulation suggests that an individual feels guilty or ashamed when they do not exercise. Results of a 2-wayANOVA indicated a significant effect over time for introjected motivation, $F(2,158)=6.61, p=.002, \eta_{\mathrm{p}}{ }^{2}=.077$ with no significant differences between groups, $F(2,158)=2.92, p=.02, \eta_{\mathrm{p}}^{2}=.045$. Overall mean scores significantly increased from 1.81 to 2.2 over time.

Introjected regulation represents a form of extrinsic motivation which is characterized by the individual internalizing external regulations (Ryan and Deci, 2002). Students in the nonchoice group experienced a more controlling style of instruction with little autonomy, which could explain the increase in introjected motivation. The students were unable to choose activities that they might find more enjoyable or comfortable; therefore, they participated because they felt an obligation to meet the needs of the course expectations. While not significant, the choice group experienced an increase in this form of regulation from Time 1 $(M=1.8)$ to Time $2(M=2.0)$ and a slight decrease from Time $2(M=2.0)$ to Time $3(M=1.9)$. The choice group could still have been grappling with the fact that, regardless of their choice in activity, they still had to meet the expectation of the course, which was to engage in a PA session during the class meeting time. Additionally, the drop in introjected regulation from Time 2 to Time 3 for the choice group could signify that these students transitioned toward identified or intrinsic regulation and were no longer motivated by feelings of guilt or shame. According to Ryan and Deci (2000), this type of regulation is extremely interesting due to the fact that the regulatory process is within the person, however, at the same time is relatively external to the self. 
Amotivation. Amotivation is the lowest level of self-determination. This suggests that an individual has no desire to exercise and does not see any reason why they should exercise (Ryan \& Deci, 2000). No significant difference was found in amotivation over time, $F(2,158)=$ $.04, p=.95, \eta_{\mathrm{p}}{ }^{2}=.001$. Additionally there was no significant difference between groups, $F(2$, $158)=.21, p=.80, \eta_{\mathrm{p}}^{2}=.003$. Overall amotivation scores were very low [Time $1(M=.15)-$ Time $3(M=.27)$ ], which suggests that most participants in the study had some form of motivation for PA. While differences were not significant, amotivation scores from Time 3 were lower than Time 1 (baseline) for both groups (see Figure 5), which could indicate that these students transitioned into some form of motivation.

Physical Activity. The amount of PA an individual engaged in over the previous seven days was collected on three separate occasions and recorded in a MET equivalent score. The scores were compared over time and between groups. A significant effect over time was found for PA, $F(2,158)=5.63, p=.004, \eta_{p}^{2}=.067$ with no significant difference between groups, $F(2$, $158)=1.34, p=.26, \eta_{p}{ }^{2}=.017$. Overall mean scores significantly improved from 52.19 to 61.46 over time indicating participants were more physically active at the end of the semester than at the beginning.

Baseline mean scores for both groups were very similar and suggest that participants were a relatively active group collectively. These findings suggest that Fitness for Life as a required health and wellness course positively impacted PA levels and added support for these course requirements. The fact that Fitness for Life is a core curriculum course means that each instructor follows similar guidelines and addresses the same subject matter. The "dosing" of subject matter delivered in class did not change among groups, which could be a reason for the lack of difference in PA levels between groups. While not significant, the choice group showed a 
decrease in mean PA scores from 60.19 (Time 2) to 57.08 (Time 3). One hypothesis for explaining this drop in the choice group could be that participants might have decreased their intensity levels during the activity days due to the timeframe falling within the last week of classes and resulting competing priorities faced by college students during this time. The choice group could have selected activities with varied intensity levels which may have affected the overall LTEQ scores. Intensity levels in the non-choice group, on the other hand, may have remained consistent throughout the semester because the instructor was leading the activity and may have chosen activities that required a higher intensity level. In addition, self-reported behavioral data may not be entirely accurate (Keating et al., 2005), which could potentially explain the drop in scores.

\section{Student Experiences in Choice vs Non-choice Teaching Style}

Analysis of the open-ended questions revealed that an overwhelming majority of participants in both choice and non-choice preferred to have freedom of choice. Table 6 shows a sample of participant responses regarding their feelings about choice. The one participant who did not prefer choice suggested instead that there were too many choices. This supports the notion that individuals who lack experience and knowledge in PA settings may find themselves overwhelmed with what to do in a choice setting (Chaubal, 2011). Additionally, because of the lack of knowledge or experience, it may be difficult for that individual to choose activities that they think might be enjoyable.

There were some participants from the non-choice group who were indifferent and/or supportive of not having a choice, but the overall majority in the non-choice group would have preferred to have choice and expressed their dislike for non-choice. They explained that they would prefer to choose activities they enjoy or would feel comfortable engaging in. Some of the 
responses included: “activities felt forced on us," "I hated lifting," "I didn't like not doing what I wanted," and "I did not like having to divert from my own workout plan." There were, however, a few participants in the non-choice group who were seemingly indifferent and implied that the non-choice class allowed them to experience new activities that they may not have experienced had they not been exposed. Some of these responses include: "I did not like not having a choice but grew to understand it," "it gave me a variety of opportunities to participate," and "being able to try new activities that I would not typically think of was interesting." Overall, the majority of participant responses suggested that they would prefer to have a choice in the PA setting.

\section{Instructor Experiences Teaching Choice vs Non-choice Styles}

Overall, the instructors perceived that some form of choice ultimately presented a more positive experience for students. The issue of pre-conditioned (i.e. highly active individuals, student athletes) vs de-conditioned (i.e. not very active, novice, non-athletes) individuals was a prominent theme that emerged through the semi-structured interviews. The instructors had similar opinions on the effects of choice and non-choice on a particular individual characteristic such as pre-conditioned and de-conditioned individuals.

Instructors in both choice and non-choice saw the differing individuals (pre-conditioned and de-conditioned) as both a strength and a weakness. The choice instructors noticed that the pre-conditioned students were able to use choice in a positive way to continue a training regimen already in place or to choose activities that were motivating to them. This is supported by Ryan and Deci (2000), who suggest that individuals' inherent intrinsic regulation can flourish in the right conditions. The following interview excerpt explains this perception: 
I think the thing that they like best is that if they had certain goals that they were working on, like one of my students, [student's name], was doing some kind of a run with her brother.... But she liked being able to come in on the day before they were getting to do their long run; she did a light weight lifting workout.

For those students that had goals and were already doing programs, choice classes let them have that opportunity to be more specific in their workouts. On the other hand, the de-conditioned students seemed to lack the ability to work at an appropriate intensity level and would choose activities that were low impact and "easy".

One positive aspect of the non-choice instructional style noted by one of the instructors was that it gave the de-conditioned students some guidance in decision making with regard to their activity choices. Additionally, one instructor pointed out "they lack the information to make exercise decisions for themselves and they don't know the fundamentals of it or the importance of it”.

The choice and non-choice teaching styles can affect the pre-conditioned and deconditioned individuals differently. This phenomenon was a developing theme that emerged from the interviews as a possible barrier to choice. Some de-conditioned students may have found more value in non-choice, where the pre-conditioned individual may have found nonchoice demotivating. Research suggests that an individual's feeling of competence will not alone impact intrinsic motivation, but that there must be an association with some sense of autonomy in order to fully impact intrinsic regulation (Ryan \& Deci, 2000). The pre-conditioned students are generally competent movers; however in the non-choice setting, they seemed less motivated due the lack of autonomy or choice. One instructor described how non-choice may have been demotivating for the pre-conditioned individual in the following excerpt: 
...it was those students that are already proficient, the athletes a lot of time who are demotivated. It was also difficult because some of the athletes worked out prior to class anyway.... They have specific goals they are already committed to and so being told you have to exercise according to this, it was demotivating. I feel anytime you take away autonomy, when it comes to PA, that can be demotivating, especially for people that already believe that they are proficient at the motor skill of exercise or cognitively. They feel that they have a sound understanding of exercise. I think that when you take away that ownership they find that demotivating.

In the choice group, the de-conditioned individuals generally found it difficult to selfmotivate while the pre-conditioned individuals thrived by finding activities that they were already doing or that could benefit their goals already in place. This was not the case, however, for all de-conditioned individuals in the choice group. One instructor described how choice allowed one of her students to find activities that were enjoyable and comfortable:

Like one girl, she's been a non-traditional student and she's gained quite a bit of weight as she's gotten older. She said she found a couple of really good workouts online and used them in class. In that sense, it made some of those kids that really didn't have any goals, help them set some goals for themselves.

One instructor of the non-choice group suggested that the de-conditioned students may benefit from non-choice because they were presented with activities that they may not have chosen nor had prior knowledge of, as highlighted by the following quote: I think it's definitely the right way to start with, especially for inexperienced and the deconditioned students it gives them the guidance that they need and it also helps motivate 
them knowing that they were receiving sound guidance. It wasn't just guessing on their part.

One barrier that emerged from the choice instructors was that some students were not meeting an appropriate intensity level for their ability. Specifically, instructors found that choice allowed students who were not particularly motivated to do the minimum intensity required. One instructor explains this in the following excerpt:

So, I think they like being able to choose the type of workout that they want to spend their time doing. Now I don't necessarily know that it was any more motivating for those kids-who didn't want to work out anyway, because I think those kids never really work to the intensity level that is high enough to give those real benefits, they were just moving. I mean, at least they did something. But it would have been even harder to get those kids to do something if I would have dictated a specific sport or specific activity for them.

Another barrier suggested by one instructor in the non-choice group was that students in this group were not in control of their activity choices and instructors were using a controlling teaching strategy. Deci and Ryan (1987) suggested that controlling teaching strategies decrease an individual's feeling of self-determination, which ultimately threatens intrinsic motivation and performance. It appears that the majority of students preferred to make their own choice of activity and were less enthusiastic about the activities provided by the instructors.

The instructors all suggested that offering choice and creating an autonomous, selfdirected environment was the ideal situation. They unanimously agreed that students preferred choosing their own activities specific to their individual skills, goals, and inclinations. Each of the instructors agreed that a gradual progression toward autonomy, specifically for the deconditioned students, would be ideal, as explained in the following excerpt: 
They may feel overwhelmed at first, I think maybe having scheduled activities early on might get them involved a little bit more but I don't think that they necessarily benefit as much.... later on you could turn to choice. Because of their interest, I think having the set schedule early on will get them involved with their classmates a little bit more. They would eventually feel comfortable enough to do their own activities.

The theoretical framework associated with adult learning proposes that there is a shift from the instructor as the authoritative figure toward the instructor as a provider of guidance and scaffolding for student learning (Furtack \& Kunter, 2012). The results from this shift suggest that the students learn to become autonomous participants responsible for creating meaningful learning experiences.

\section{Limitations}

While the results of this study indicate significant findings, there are some limitations that should be acknowledged. The relatively small sample size could have a potential impact on the generalizability of the study. In addition, since the study took place in a small liberal arts institution, the results may not generalize to other institutions of different size/aims. Another potential limitation is instructor bias. Because different instructors employed different teaching strategies, it may have been difficult to determine whether differences in student motivation occurred because of the instructor's personality, gender, or overall teacher effectiveness. Finally, the length of the intervention could also be a limitation. The 15-week semester may not have been sufficient time to see an effect in teaching styles.

\section{Conclusion and Future Research}

Results from this study suggest that college students experienced a significant improvement in autonomous motivation and PA over time as a result of participation in a Fitness 
for Life class. Behaviors that students develop during college years have been found to have a long-term impact on adult habits relating to maintaining PA (Keating et al. 2005). Implications from this study provide evidence for continued research and support for higher education PA programs (HEPAP) as an effective strategy for improving health and PA patterns in young adults. Given the amount of resources invested in teaching Fitness for Life courses at universities nationwide, results from this study may help to plan and develop curricular revisions within these courses.

Previous studies on motivation (mainly at the K-12 level) are in agreement that treatment environments affording autonomy and supporting confidence are likely to enhance adherence and health outcomes (Ryan, Patrick, Deci, \& Williams, 2008). According to the adult learning theory, the self-concept of the adult learner suggests the need for autonomy and self-directed learning. Knowles, (1977) suggested that instructors should focus on facilitating situations that move the learner from dependency to more self-directness, which was conveyed by the instructors during the semi-structured interviews. This study provides additional support for adults' desire for autonomy and self-directness within college Fitness for Life courses.

While there were no statistically significant findings that suggested exposure to choice was superior to non-choice in this study, findings do suggest that the overall course itself was able to positively impact PA levels. This lends additional support for the effectiveness of required college health and wellness courses. Participants in both choice and non-choice groups overwhelmingly expressed a desire to have freedom of choice in the PA setting. Additionally, instructors expressed the need to facilitate the increase of autonomy (choice) among students in the Fitness for Life setting, which supports the key components associated with the adult 
learning theory that suggest that students need a gradual progression from dependency toward more autonomy and self-directedness (Knowles, 1977).

The fact that there were no significant differences in motivation and PA among choice and non-choice groups also suggests that the course experience itself had more of an impact on motivation than the teaching style of choice and non-choice. It is suggested that future research involve more control over the variable of choice and non-choice. One example for controlling this variable is for the non-choice instructors to follow a pre-determined curriculum in an attempt to reduce instructor bias and isolate the variables of interest. Future research should further consider the use of a crossover design in which participants experience both choice and nonchoice throughout the semester. This would allow participants to make a distinction between choice and non-choice group experiences independent of the course experience itself.

Future research is warranted to determine whether PA levels are maintained after completion of the course, and for how long. Since it is known that autonomous motivation leads to greater persistence in a behavior (Sibley et al., 2013), future research should focus on how students' ability to become autonomous in their PA choices can impact motivation. Additionally, instructors from this study concluded that implementing strategies that gradually increase autonomy and self-directedness in students throughout the semester may be an optimal way to improve intrinsic motivation towards PA. Therefore, working with college instructors to facilitate and guide students toward greater autonomy and self-directedness within Fitness for Life course through professional development workshops or online learning modules is suggested. Increasing PA among an increasingly sedentary population could have a profound effect on individuals' overall health as well as add to the growing body of literature on motivation. 


\section{References}

Alemeda, A. (2009). Effect of a 15-week wellness course on health indicators and six areas of wellness in college students, (Doctoral dissertation). retrieved from ProQuest. (3544507)

American College Health Association. (2012, June). Healthy Campus 2020. Retrieved March 2014, from http://www.acha.org/HealthyCampus/index.cfm

American Heart Association. (2014). The price of inactivity. Retrieved March 2014, from http://www.heart.org/HEARTORG/GettingHealthy/PhysicalActivity/The-Price-of Inactivity_UCM_307974_Article.jsp

Brunet, J., \& Sabiston, C. (2011). Exploring motivation for physical activity across a lifespan. Psychology of Sport and Exercise, 12, 99-105. doi:10.1016/j.psychsport.2010.09.006

Chaubal, S. (2011). Effect of knowledge of exercise benefits on attitude, motivation, and exercise participation, (Master's Thesis). State University of New York, Cortland.

Clark, V. \& Creswell, J. (2008). The mixed methods reader. Los Angeles: Sage Publications, Inc

Deci, E. \& Ryan, R. (1985). Intrinsic Motivation and self-determination in human behavior. New York, Plenum Press.

DeLong, L. (2006). College students' motivation for physical activity. (Doctoral dissertation)

Gale, N., Heath, G., Cameron, E., Rashid, S., \& Redwood, S. (2013). Using the framework method for the analysis of qualitative data in multi-disciplinary health research. $B M C$ Medical Research Methodology, 13(117), 1-8. doi: http://www.biomedcentral.com/1471$2288 / 13 / 117$ 
Godin, G. (2011). The Godin-Shephard leisure-time in exercise questionnaire. Health and Fitness Journal of Canada, 4(1), 1-7.

Godin, G. and Shephard, R. (1985). A simple method to assess exercise behavior in the community. Canadian Journal of Applied Sport Science 10, 141-146.

Hagger, M., Chatzisarantis, N., Culverhouse, T., \& Biddle, S. (2003). The process by which perceived autonomy support in physical education promotes leisure-time physical activity intentions and behavior: A trans-contextual model. Journal of Educational Psychology, 95(4), 784-795.

Hardin, R., Andrew, D.P., Koo, G., \& Bemiller, J. (2009). Motivational factors for participating in basic instruction programs. Physical Educator, 66(2), 71-85.

Hensley, L. (2000). Current status of basic instruction programs in physical education at American colleges and universities. Journal of Physical Education, Recreation \& Dance. 7l(9). 30-36. doi:10.1080/07303084.2000.10605719

Keating, X., Guan, J., Pinero, J., \& Bridges, D. (2005). A meta-analysis of college students' physical activity behaviors. Journal of American College Health, 54(2), 116-125.

Kilpatrick, M., Hebert, E., \& Bartholomew, J. (2005). College students' motivation for physical activity: Differentiating Men's and Women's motives for sport participation and exercise. Journal of American College Health, 54(2), 87-94.

Knowles, M. (1977) Adult learning processes: Pedagogy and andragogy. Religious Education. 72(2), 202-210.

Knowles, M. (2011). The adult learner: The definitive classic in adult education and human resource development, (7th ed.). Amsterdam, The Netherlands: Elsevier. 
Leslie, E., Sparling, P., \& Owen N. (2001). University campus settings and the promotion of physical activity in young adults: lessons from research in Australia and the USA. Health Education, 101(3), 116-125. Retrieved from http://www.emerald-library.com/ft

Lumpkin, A. (1993). Basic instruction programs: A brief history. Journal of Physical Education Recreation and Dance, 64, 32-36.

Markland, D., \& Tobin, V. (2004). A modification to the behavior in exercise regulation questionnaire to include an assessment of amotivation. Journal of Sport and Exercise Psychology. 26, 191-196

Medero, M. (2012). The effectiveness of a conceptually-based health and wellness course in developing health related factors, exercise self-efficacy and knowledge of health issues and exercise performance among diverse college students. (Doctoral dissertation).

Norman, G, \& Streiner, D. (2008). Biostatistics: The bare essentials. Hamilton, B.C. Decker.

Pearman, S. (1995). The impact of a required college health and physical education course on the health status of alumni. Journal of American College Health, 46(2), 77-85.

Pethkar, V., Naik, S., \& Sonawane, S. (2010). Attitude toward physical activity and its measurement. Journal of Physical Education and Sport, 29(4), 30-36.

Reeve, J., Jang, H.,Carrell, D., Jeon, S., \& Barch, J. (2004). Enhancing students' engagement by increasing teachers' autonomy support. Motivation and Emotion, 28(2), 147-169. doi: 0146-7239/04/0600-0147/0

Ryan, R. \& Deci, E. (2000). Self-determination theory and the facilitation of intrinsic motivation, social development, and well-being. American Psychologist, 55(1), 68-78. doi: 10.1037110003-066X.55.1.68

Ryan, R. \& Deci, E. (2007) Active human nature: self-determination theory and 
the promotion and maintenance of sport, exercise, and health. In M. S. Hagger \& N. L. D. Chatzisarantis (Eds.), Intrinsic motivation and self-determination in exercise and sport. Champaign, IL: Human Kinetics. Pp. 23-34.

Ryan, R., Kuhl, J., \& Deci, E. (1997). Nature and autonomy: A organizational view of social and neurobiological aspects of self-regulation in behavior and development. Development and Psychopathology, 9, 701-728.

Ryan, R., Patrick, H., Deci, E., \& Williams, G. (2008). Facilitating health behavior change and its maintenance: Interventions based on self-determination theory. European Health Psychology Society, 10(1), 1-23.

Sallis, J. (2000). Age-related decline in physical activity: a synthesis of human and animal studies. Medicine and Science in Sports and Exercise, 1598-1600. doi: 01959131/00/3209-1598/0

Sibley, B., Hancock, L., \& Bergman, S. (2013). University students' behavioral regulation, motives, and physical fitness. Perceptual and Motor Skills: Exercise and Sport. 116(1), 322-339. doi: 10.2466/06.10.PMS.116.1.322-339

Standage, M., Duda, J., \& Ntoumanis, N. (2003). A model of contextual motivation in physical education: Using constructs from self-determination and achievement goal theories to predict physical activity intentions. Journal of Educational Psychology, 95(1), 97-110. doi: 10.1037/0022-0663.95.1.97

Stevens, J.P (2009). Applied multivariate statistics for the social sciences (5th Ed.). Routledge, Publishers. New York, NY.

Westbrook, L. (2005). Problem-based learning: A staff development model for tight budget times. Technical Services Quarterly, 21(1), 27-33. 
Young, N. (2012) Effective learning and teaching of RDA: Applying adult learning theory, Journal of Library Metadata, 12(2-3), 188-198.

\section{Table 1}

Cronbach's Alpha coefficient

\begin{tabular}{lll}
\hline BREQ-2 subscale & $\alpha$ choice & $\alpha_{\text {non-choice }}$ \\
\hline External Regulation & .77 & .69 \\
Intrinsic Regulation & .94 & .87 \\
Identified Regulation & .87 & .79 \\
Introjected Regulation & .77 & .74 \\
Amotivation & .74 & .60 \\
\hline
\end{tabular}


Table 2

Chi-square results for Gender, year in school, student athlete status, and reason for registration

\begin{tabular}{lccc}
\hline \multicolumn{1}{c}{ Measure } & Chi-square & $d f$ & Sig. \\
\hline Gender & 8.30 & 1 & .40 \\
Year in School & 4.15 & 3 & .24 \\
Student Athlete & 1.88 & 1 & .23 \\
Reason for & 5.89 & 4 & .20 \\
Registration & & & \\
\hline$p>.05$ & & &
\end{tabular}


Table 3

Results of Independent T-tests for BREQ-2 subscales, LTEQ, and GPA by choice and nonchoice group

\begin{tabular}{lccccc}
\hline \multirow{2}{*}{ Measure } & \multicolumn{2}{c}{ Choice group $(\mathrm{N}=37)$} & \multicolumn{2}{c}{ Non-choice group $(\mathrm{N}=44)$} & \multirow{2}{*}{ Sig. } \\
\cline { 2 - 5 } & Mean & SD & Mean & SD & \\
\hline LTEQ & 52.16 & 32.01 & 52.20 & 28.30 & .99 \\
External regulation & .58 & .75 & .77 & .82 & .28 \\
Intrinsic regulation & 2.58 & 1.18 & 2.84 & .91 & .26 \\
Identified regulation & 2.64 & 1.09 & 3.00 & .78 & .08 \\
Introjected regulation & 1.84 & 1.38 & 1.78 & 1.16 & .82 \\
Amotivation & .27 & .58 & .16 & .41 & .33 \\
GPA & 2.22 & 1.22 & 2.07 & 1.22 & .64 \\
\hline
\end{tabular}

$P<.05$ 
Table 4

Two-Way Analysis of Variance of the 5 subscale measures of the BREQ-2 and LTEQ by time and choice/non-choice group

\begin{tabular}{|c|c|c|c|c|}
\hline & $\mathrm{MS}$ & $d f$ & $\mathrm{~F}$ & $p$ \\
\hline \multicolumn{5}{|c|}{ External Regulation } \\
\hline Time & .56 & 2 & 1.98 & .14 \\
\hline Time*Group & .07 & 2 & .24 & .78 \\
\hline \multicolumn{5}{|c|}{ Intrinsic Regulation } \\
\hline Time & 2.67 & 2 & 10.13 & .00 \\
\hline Time*Group & .11 & 2 & .42 & .65 \\
\hline \multicolumn{5}{|c|}{ Identified Regulation } \\
\hline Time & 1.44 & 2 & 7.35 & .00 \\
\hline Time*Group & .20 & 2 & 1.03 & .35 \\
\hline \multicolumn{5}{|c|}{ Introjected Regulation } \\
\hline Time & 2.93 & 2 & 6.61 & .00 \\
\hline Time*Group & 1.66 & 2 & 3.74 & .02 \\
\hline \multicolumn{5}{|l|}{ Amotivation } \\
\hline Time & .00 & 2 & .04 & .95 \\
\hline Time*Group & .02 & 2 & .21 & .80 \\
\hline \multicolumn{5}{|l|}{ LTEQ } \\
\hline Time & 1908.33 & 2 & 5.63 & .00 \\
\hline Time*Group & 454.65 & 2 & 1.34 & .26 \\
\hline
\end{tabular}


Table 5

Means and Standard Deviations (SD) on the 5 subscale measures of the BREQ-2 by choice and non-choice group

\begin{tabular}{lllllll}
\hline & \multicolumn{2}{c}{ Round 1 } & \multicolumn{2}{c}{ Round 2 } & \multicolumn{2}{c}{ Round 3 } \\
\cline { 2 - 7 } & Choice & $\begin{array}{l}\text { Non- } \\
\text { choice }\end{array}$ & Choice & $\begin{array}{l}\text { Non- } \\
\text { choice }\end{array}$ & Choice & $\begin{array}{l}\text { Non- } \\
\text { choice }\end{array}$ \\
\hline \multirow{2}{*}{\begin{tabular}{l} 
External Regulation \\
\cline { 2 - 7 }
\end{tabular}} & $.58(.75)$ & $.77(.82)$ & $.79(.87)$ & $.89(.86)$ & $.65(.79)$ & $.87(.82)$ \\
Intrinsic Regulation & $2.5(1.1)$ & $2.8(.91)$ & $2.9(.93)$ & $3.0(.82)$ & $2.9(.88)$ & $3.1(.75)$ \\
Identified Regulation & $2.6(1.0)$ & $3.0(.78)$ & $2.9(.83)$ & $3.1(.61)$ & $2.9(.82)$ & $3.1(.60)$ \\
Introjected & $1.8(1.3)$ & $1.7(1.1)$ & $2.0(1.1)$ & $2.0(1.1)$ & $1.9(1.2)$ & $2.4(1.0)$ \\
Regulation & $.27(.58)$ & $.16(.41)$ & $.22(.48)$ & $.17(.40)$ & $.25(.51)$ & $.15(.35)$ \\
Amotivation & & & & & & \\
\hline
\end{tabular}


THE IMPACT OF CHOICE

Table 6

Sample of Responses by Group

\begin{tabular}{|c|c|c|}
\hline $\begin{array}{c}\text { Choice Group } \\
\text { ( why they preferred) }\end{array}$ & $\begin{array}{l}\text { Non-choice Group } \\
\text { (why they did not } \\
\text { preferred) }\end{array}$ & $\begin{array}{l}\text { Non-choice Group } \\
\text { (why the preferred) }\end{array}$ \\
\hline $\begin{array}{l}\text { Like being able to choose } \\
\text { activities based on fitness goals }\end{array}$ & $\begin{array}{l}\text { Did not like having to divert } \\
\text { from own workout plan }\end{array}$ & $\begin{array}{l}\text { Did not like not having a } \\
\text { choice but grew to } \\
\text { understand it }\end{array}$ \\
\hline $\begin{array}{l}\text { Liked choosing activities that } \\
\text { you are comfortable with. }\end{array}$ & Activities felt forced upon us & $\begin{array}{l}\text { Gave me a variety of } \\
\text { opportunities to participate }\end{array}$ \\
\hline $\begin{array}{l}\text { Liked being able to choose } \\
\text { something fun for individual }\end{array}$ & $\begin{array}{l}\text { Did not have fun with } \\
\text { certain activities }\end{array}$ & $\begin{array}{l}\text { Being able to try new } \\
\text { activities that I would not } \\
\text { typically think of was } \\
\text { interesting }\end{array}$ \\
\hline Loved having a choice, freedom & I hated lifting & I enjoyed having options \\
\hline $\begin{array}{l}\text { Able to choose activities that I } \\
\text { like and know }\end{array}$ & $\begin{array}{l}\text { I did not enjoy not having a } \\
\text { choice }\end{array}$ & \\
\hline $\begin{array}{l}\text { Enjoyed choosing activity, can } \\
\text { focus on what my body can do } \\
\text { and what part of my body I want } \\
\text { to work on }\end{array}$ & $\begin{array}{l}\text { I don't like working out with } \\
\text { a group of people }\end{array}$ & \\
\hline $\begin{array}{l}\text { Allowed me to improve on what } \\
\text { is most beneficial to me } \\
\text { Workouts specific to my } \\
\text { enjoyment and body type }\end{array}$ & $\begin{array}{l}\text { Didn't like not doing what } \\
\text { we wanted to }\end{array}$ & \\
\hline
\end{tabular}




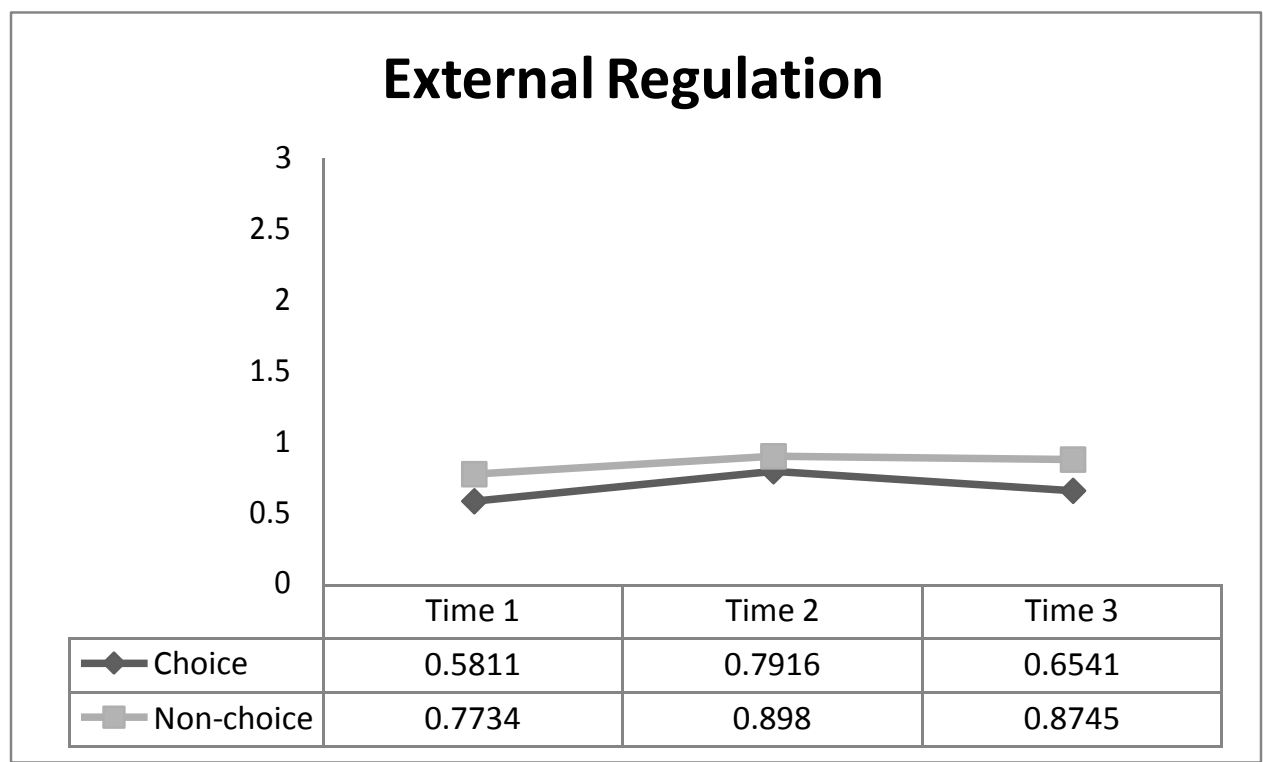

Figure 1. Line graph shows differences over time in external regulation between choice and nonchoice groups. 




Figure 2. Line graph shows differences over time in intrinsic regulation between choice and nonchoice groups. 


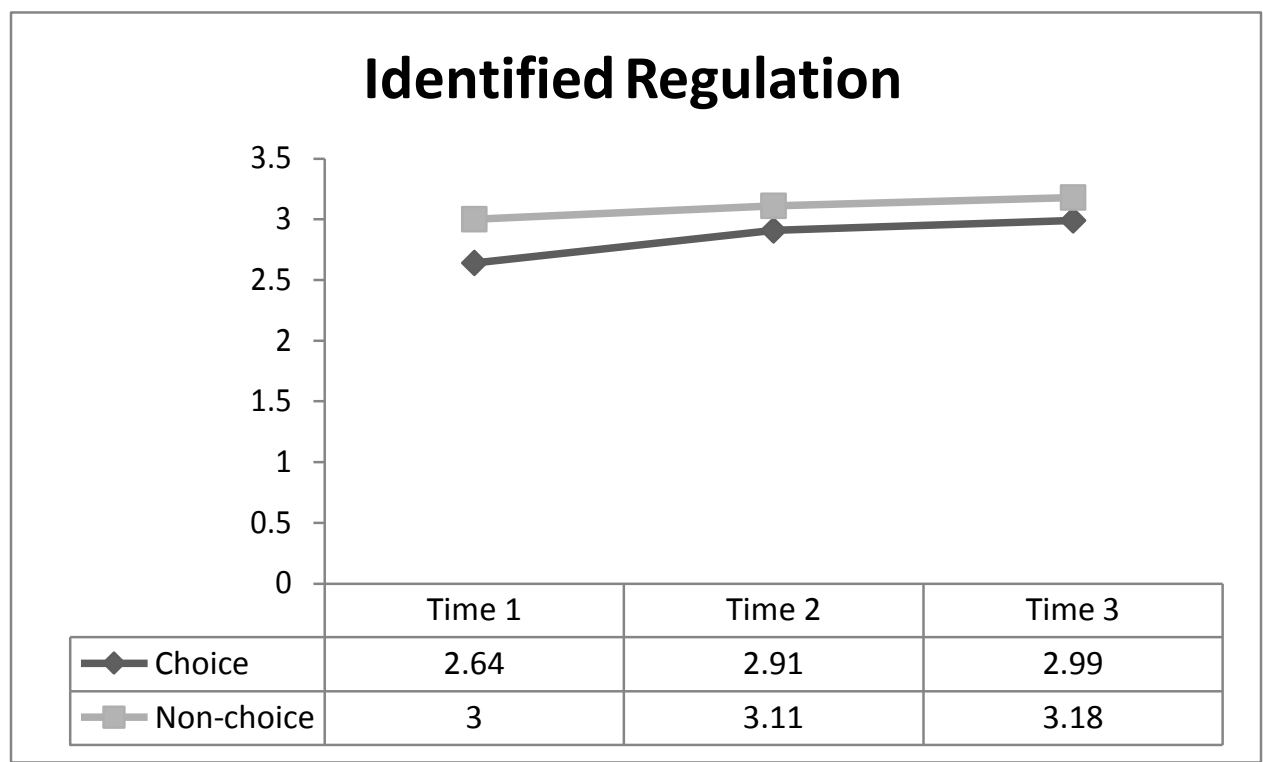

Figure 3. Line graph shows differences over time in identified regulation between choice and non-choice groups. 


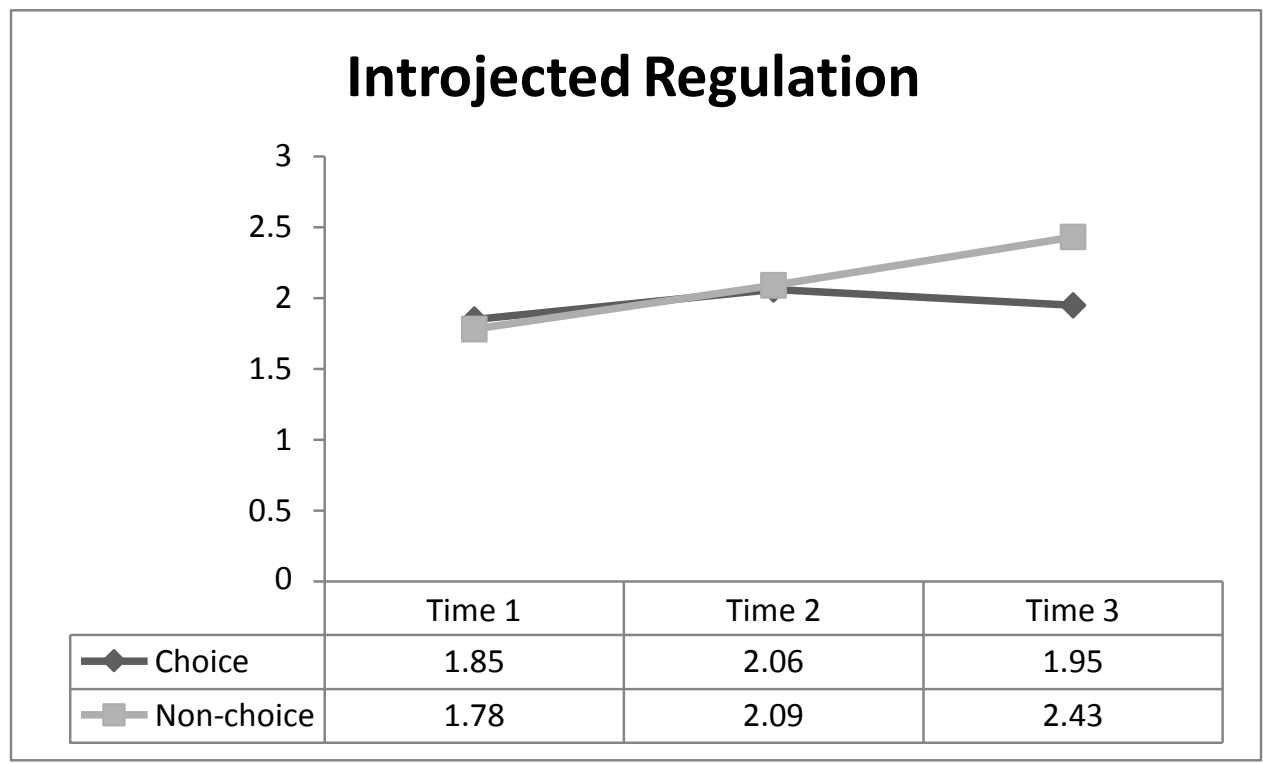

Figure 4. Line graph shows differences over time in introjected regulation between choice and non-choice groups. 


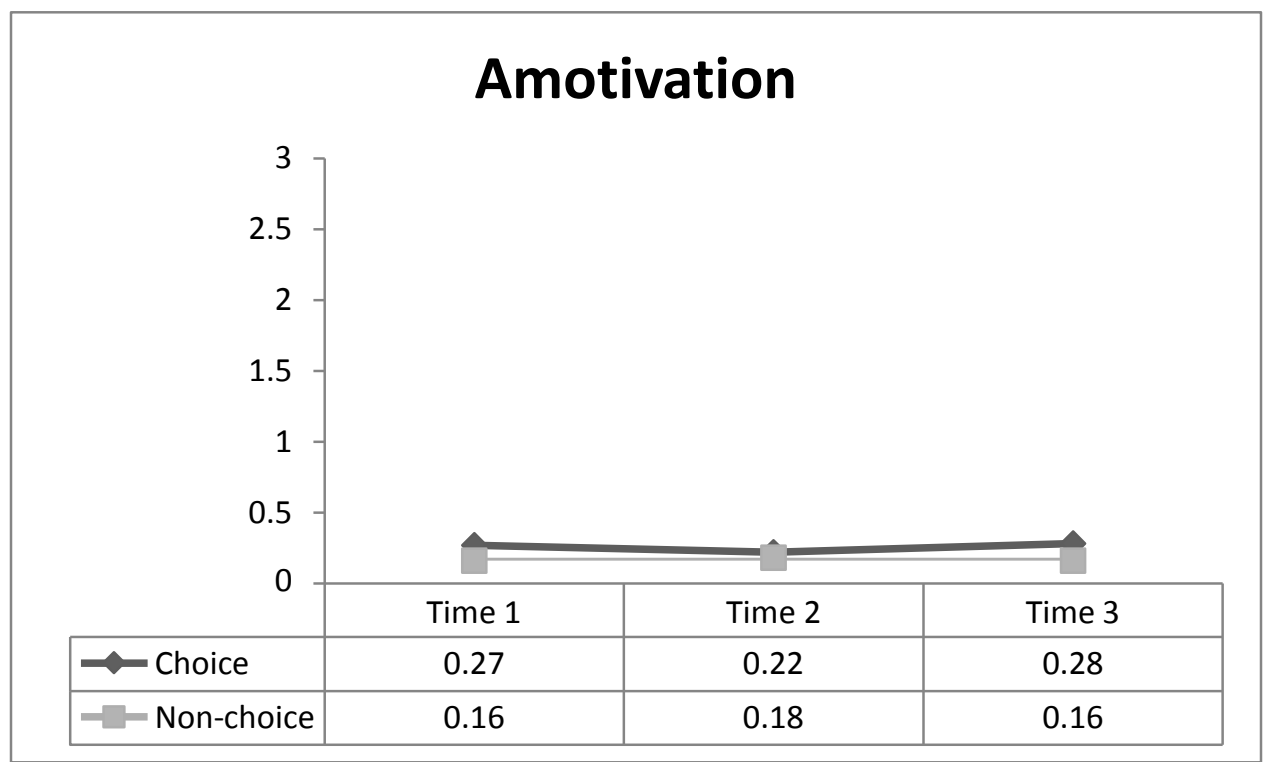

Figure 5. Line graph shows differences over time in amotivation between choice and non-choice groups. 


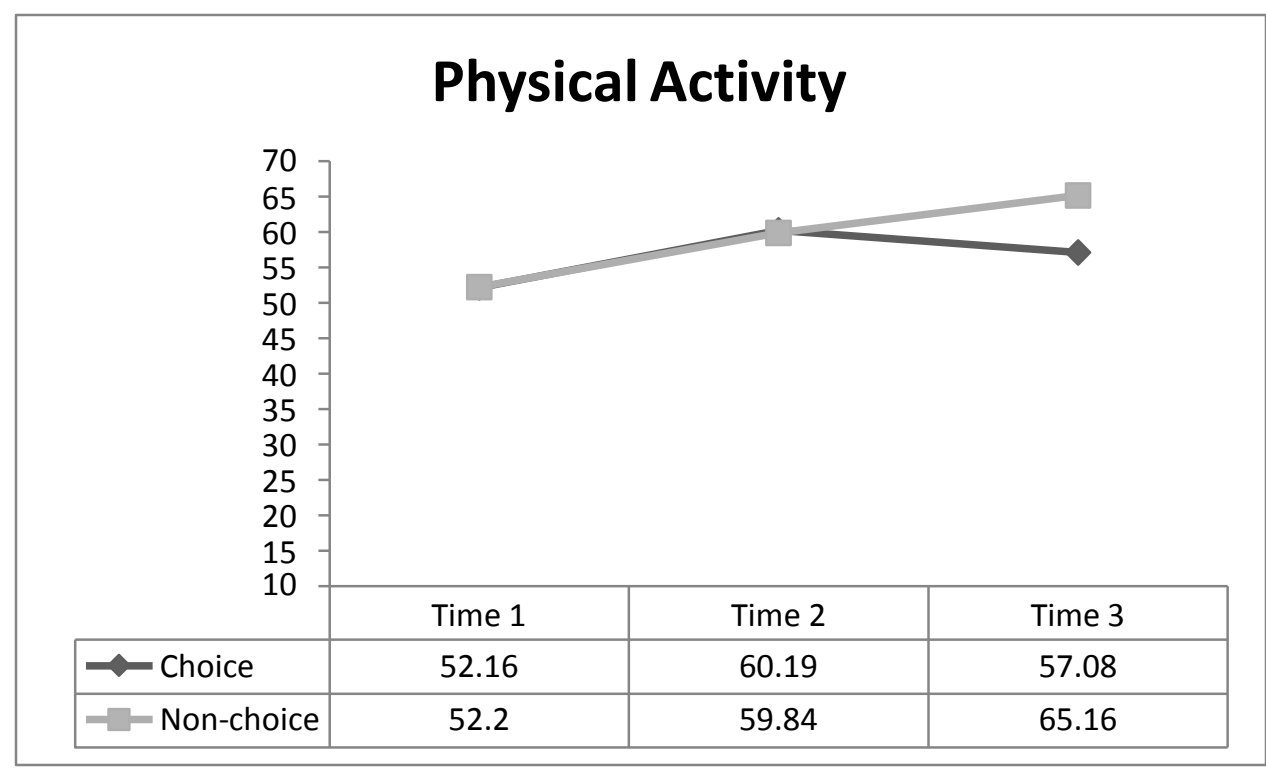

Figure 6. Line graph shows differences over time in physical activity between choice and nonchoice groups. 


\section{Appendix A}

\section{Review of Literature}

\section{College Physical Education}

The American College Health Association's (2012) Healthy Campus initiative states that U.S. colleges and universities serve 20 million students and employ 3.5 million people. These institutions of higher education, therefore, serve as living, learning, and working environments which impact the health of students, faculty, and staff (American College Health Association, 2012). Research related to wellness behaviors has the potential to affect large numbers of stakeholders in the college environment (LaFountaine, Neisen, \& Parsons, 2006).

Physical education (PE) programs have been taught in American college and universities for over 100 years (Hensley, 2000). In the late 1800's, college PE classes were designed to increase students' strength, endurance, health and overall well-being (Lumpkin, 1993). College PE programs would emerge and evolve over the years. During WWI and WWII, the focus on training soldiers strengthened physical education programs in higher education (Sparling, 2003). Lifetime activities and skills became popular in the 1960's (Lumpkin, 1993). Additionally at this time, PE courses developed into a conceptually-based fitness/wellness model in some part due to the desire to make PE courses more "academic" (Hodges-Kulinna, Warfield, Jonaitis, Dean, \& Corbin, 2009). The conceptual-based model included a lecture-lab component which was an acceptable alternative to the activity-based model. A decline in physical education began in the 1970's (Sparling, 2003) as institutional focus changed and funding in the areas of physical education diminished.

During the 1980's, many of the larger Research 1 institutions did away with the PE requirement for general non-major PE college students. Although PE as a major field has 
developed and expanded over the years, PA courses for general non-major PE college students have remained constant (Hensley, 2000). The one thing that has not remained constant is the percentage of college and universities maintaining PE courses as a requirement for the general college student. Hensley (2000) reported that the percentage of institutions requiring PE has decreased from 90 percent in the 1960's to 65 percent in the 1990's. The percentages of required PE courses for general college students continue to decline (Hensley, 2000).

There are two main types of college PE programs. Many of the larger (greater than 5000 students) research institutions have implemented basic instruction programs (BIP). BIP courses, also referred to as activity-based PE (APE) or higher education physical education programs (HEPAP), are typically one credit and teach skill-related concepts. Smaller institutions tend to offer a more holistic health and wellness approach to their PE requirement. This multidimensional, concept-based class or conceptually-based fitness/wellness model, sometimes referred to as "Fitness for Life," is frequently a requirement in smaller institutions, which is currently about 63 percent of all colleges and universities in America (Hensley, 2000; Leslie, Sparling, \& Owen, 2001). Concept-based PE (CPE) is another term used to describe this approach to college PE. These courses were originally designed to complement skill-based classes and to provide students with additional knowledge in the area of health, fitness, and wellness (Corbin \& Cardinal, 2008). In addition, they were promoted as a practical option which implemented key concepts that would help students become active and fit throughout their lifetime (Corbin \& Cardinal, 2008).

Adams and Brynteson (1995) investigated the impact of activity-based PE framework (APE) courses and conceptually-based PE framework (CPE) courses in order to determine if there was a difference in attitudes towards fitness, knowledge of fitness, and current exercise 
habits between the alumni who participated in the APE and CPE courses. Alumni $(n=567)$ from two colleges, were surveyed; one college offered the APE framework and the other offered a CPE framework. Results suggested that the alumni who participated in the CPE courses placed a significantly greater value on their college PE program as compared to alumni who participated in the APE courses (Adams \& Brynteson, 1995). In addition, alumni who participated in the CPE courses reported engaging in significantly more PA than the alumni who participated in the APE courses. This suggests that the CPE framework may have a greater and more positive impact on health and wellness than the activity-based/skill-based framework.

The Fitness for Life conceptual framework approach, also referred to CPE, is used in approximately 52 percent of college and universities that have a PE requirement for general college students (Leslie et al., 2001). Leslie et al. (2001) also indicate that 60 percent of all institutions offer, but do not necessarily require, the multidimensional, concept-base course many times referred to as "Fitness for Life." In an article discussing the current status of basic instruction programs in PE in American institutes of higher learning, Hensley (2000) suggested that "basic instruction skills classes may likely face elimination; the trend towards conceptuallybased courses such as Fitness for Life will continue to grow" (p. 36). Regardless of the requirement, students value PA classes especially when their needs for fun, fitness, and lifetime skill development are met (Lumpkin, 1993). It is anticipated that this development could change the way young adults manage their health and wellness as well as influence a generation towards active lifestyles.

Impact of college health and wellness courses. Researchers and health specialists are more aware than ever of the benefits of regular PA (Centers for Disease Control and Prevention [CDC], 2014). PA established as young adults will typically be maintained into middle and 
older adulthood (Keating, Guan, Pinero \& Bridges, 2005). Research indicates that PA patterns steadily decrease during adulthood (Sallis, 2000), so it is important that they be established as early as possible. Leslie et al. (2001) suggest that young adults are a neglected population but an important target group for PA interventions, and campuses are pivotal settings with unrealized opportunities to influence young adults' PA patterns.

Prior studies have examined the impact of college health and wellness classes. Pearman (1995) evaluated the impact of a required college health and PE class by examining the health status of alumni. The Health Habits and History Questionnaire was distributed to 1,950 randomly-sampled alumni from two colleges, one which required the college health and PE class and one that did not. Additionally, comparisons of health knowledge, attitudes, and behaviors were examined. Survey results from alumni who participated in the college health and wellness course concluded that the required college PE class had a more positive effect on self-reported health-related knowledge, attitudes, and behavior compared to the alumni who were not required to take the class. Student health habits also had been positively influenced by participation in the college PE class, with significantly more of the participants surveyed indicating that they continued to practice positive health habits such as running and jogging. Thus, it appears that the additional experience of a required college PE class can greatly enhance one's health-related knowledge and behaviors well beyond most of the national norms (Pearman, 1995).

Medero (2012) examined the effectiveness of a conceptually-based health and wellness course, and specifically examined health-related factors, exercise self-efficacy, and knowledge of health issues and exercise performance. Participants in the study consisted of students enrolled in six sections of a health and wellness course $(n=185)$ and three sections of a student life skills course $(n=75)$. Baseline measures were collected on body composition, cardiorespiratory 
endurance, muscular strength, and muscular endurance. Additionally, baseline data on participants' knowledge of health-related topics and self-efficacy towards PA were collected. Results of the study indicated that there was a significant positive relationship between enrollment in the health and wellness course and improvement of cardiorespiratory endurance $(F$ $(1,157)=45.13, p<.001)$, muscular endurance $(F(1,169)=6.15, p=.014)$, and strength $(F$ $(1,177)=3.98, p=.047)$. The study participants enrolled in the health and wellness courses significantly improved in most of the fitness tests. Additionally, they gained knowledge on health-related topics such as nutrition. Results indicated there was a significant difference in nutritional habits between groups, $F(1,170)=6.77, p<.010$, indicating the participants enrolled in the health and wellness courses improved their nutritional habits. Participants also reported an increase in their desire to participate in physical activities and exercise self-efficacy at the completion of the health and wellness course (Medero, 2012). Consequently, Medero recommends that, to appeal to students of differing ages and abilities, a variety of PE activities be offered.

Many of the conceptually-based health and wellness courses address the six dimensions of wellness: physical, emotional, spiritual, social, intellectual, and psychological. A study by Alemada (2009) examined the outcomes of a 15-week university wellness-based course on health indicators and self-perceived wellness based on these six dimensions. The study consisted of a pre- and post-test screening. Participants $(N=124)$ were screened for health indicators including blood pressure, body composition analysis, body mass index, and resting heart rate. Results of the study indicated that participants experienced significant health benefits as well as an increase in self-perceived wellness as compared to the control group who did not participate in the 15-week wellness-based course. Specifically, there was a significant difference in body 
mass index, $t(65)=-2.128, p=.037$, and resting heart rate, $t(65)=3.135, p=.003$, for the intervention group.

These studies imply that conceptually-based college health and wellness courses can be effective. They do not, however; explain why young adults are still a very sedentary population compared to their younger counterparts (Sparling, 2003). Health and PA professionals in higher education have not been able to effectively increase and sustain university students' PA behaviors throughout adulthood. Interventions to promote students' PA are still at an early stage and have only produced moderate effects (Keating et al., 2005). Keating et al. (2005) suggested that developing strategies for increasing PA in the general population is crucial. Sedentary lifestyles are associated with an individual's increased risk of several chronic diseases such as coronary artery disease, obesity, type II diabetes, osteoporosis, depression, and anxiety, to name a few (CDC, 2014). Sparling (2003) states that, "when a large proportion of our young adult population is not engaging in healthful levels of PA, it is a dire situation that bodes poorly for the future health of the nation" (p. 582). According to the Surgeon General, and as confirmed by results of intervention studies that show only moderate overall effects of PA improvement (United States Department of Health and Human Services, 2001), students will not increase PA only because they have been told that they should.

It would seem that current methods of teaching PE at the college level have fallen short in increasing PA since young adults are still a sedentary population. Therefore, extra efforts are needed to promote additional and lasting increases in PA among college students. Such efforts could be made in the form of teaching strategies implemented during a required conceptuallybased college health and wellness course. Research in this area in warranted due to the continued 
decline in PA rates (Sparling, 2003) in young adults and subsequent increased risk of multiple chronic diseases arising from this decline.

\section{Curricular Models in Physical Education}

There are multiple curricular models in PE that have evolved and been adapted over the years. Kulinna (2008) presented an overview detailing eight current curricular models: sport education, tactical games, multiactivity, movement education, personal-social responsibility, outdoor recreation and adventure education, health-related physical education, and interdisciplinary curriculum. Of these, sport education model, health-related PE, personal-social responsibility, and interdisciplinary curriculum models have been most influential in the literature.

Siedentop (1994) developed the sport education model to be an authentic sports experience including a full season with teams, coaches, statisticians, referees, journalist, practice sessions, games, and championships. The sport education model aims to provide an authentic experience by incorporating many of the features of authentic sport within PE (Hastie, 1996). The purposes of sport education are best achieved through combinations of direct instruction, cooperative small-group work, and peer teaching rather than by total reliance on directive, drilloriented teaching (Siedentop, 1998). In this model, everything that is taught or learned in PE happens in the context of developmentally appropriate forms of sport (Kulinna, 2008). Layne and Piipari (2015) recent investigated the impact of the sport education model on students' game performance and content knowledge in basketball at the college level. Thirty-six university students from two PA courses took part in the study. One class was taught using the sport education model and the other used a more traditional approach. Game efficacy, offensive game performance, and content knowledge were measured. Results indicated that there was a 
significant difference between offensive game performance $(F=26.21, p<.001, \eta 2=.19)$ and content knowledge $(F=25.23, p<.001, \eta 2=.50)$ between groups. There was no significant difference, however, within groups for sport education $(\mathrm{F}=.075, p=.786)$ and traditional $(\mathrm{F}=$ $.436, \mathrm{P}=.516)$. Results from this study lend additional support for the effectiveness of the sport education model in improving skills and knowledge in a sport context.

The health-related PE model focuses on increasing the percentage of moderate to vigorous PA (MVPA) accumulated during PE class. Health-related PE curricula place a high priority on students developing physically active behaviors both inside and outside class (Kulinna, 2008). The focus on increasing MVPA is believed to contribute to health-enhancing outcomes. With lack of PA being recognized as a risk factor for cardiovascular disease, some physical educators are arguing that it is more important to improve PA rather than fitness, recognizing that PA is a behavior facilitating physical fitness, which is a biological characteristic. Currently Sports Play and Active Recreation for Kids (SPARK) is one of the most effective programs in the health-related PE curriculum (Sallis, Mackenzie, Alcaraz, Kolody, Faucette, \& Hovell, 1997). This thorough program was written and designed for both classroom and PE specialists, as not all states require PE to be taught by a specialist (National Association for Sport and Physical Education (NASPE) \& American Heart Association, 2012).

Hellison (1996) developed the personal and social responsibility model. This model was designed to help young people become more personally responsible for their own well-being and the well-being of others. This model is based on personal and social responsibility goals and strategies, which according to the model, should be integrated into the PE lessons rather than being taught separately. A key component of this curriculum is being able to transfer 
experiences from the activity setting to other areas of life with the intention of helping students learn to become more personally and socially responsible.

The last of the main four models in PE is interdisciplinary curriculum, which offers the possibility of defining the unique contribution PE has on schools by giving students richer learning experiences, by forcing introspection through working with teachers in other subjects, and by helping students see PE as an important part of the school curriculum and of life (Placek, 1996). Interdisciplinary models focus on enhancing student learning by addressing key concepts in a variety of domains (Kulinna, 2008). Examples of these concepts may include mathematics and literacy. The interdisciplinary curriculum benefits students by enriching learning across academic disciplines, while appreciating the knowledge and expertise brought by other teachers (Solomon \& Murata, 2008).

Choice curriculum. The idea of giving students a choice in physical activities has emerged in order to improve motivation levels, which are a foundation for an individual's persistence in exercise. Individuals who can discover an activity in which they find internal fulfillment will likely increase their intrinsic motivation towards that activity, increasing time spent in that activity.

In recent years there have been efforts made to incorporate a component of choice into the PE curriculum. While choice curriculum is not a documented curricular model in the literature, offering choice to students in PE classes has been the topic of multiple studies at the K-12 level. Within most middle and high school PE departments, there are multiple teachers with multiple classes conducting physical education at the same time. This gives teachers the ability to adapt the curriculum so that there is an element of choice for the students. For example, there would be a selected number of activities (i.e. aerobics, dance, or kickboxing), 
each taught by a different instructor during the same class time. Students would be able to choose among the activities offered. Since school systems maintain a set of desired outcomes, complete choice with regards to PA would be difficult within the K-12 curriculum. Most of the studies conducted on choice curriculum have incorporated a controlled set of activities or units from which the students could choose.

For example, in a study by Campbell (2012), ninth and tenth grade students $(N=137)$ participated in a three-week choice curriculum unit. The purpose of the study was to investigate how offering activity choices in a PE setting would impact students' perceived autonomy, perceived competence, motivation, enjoyment, and number of dress-out days (Campbell, 2012). Students were able to select between two different activities in each of the three weeks. Additionally, students participated in a three-week non-choice program where they participated in teacher-led activities. Perceived autonomy was measured using a 5-item questionnaire, perceived competence was measured using a 3-item questionnaire developed by the researcher, motivation was measured using a modified version of the 14-item Situational Motivation Scale (SIMS), enjoyment was measured using a 4-item questionnaire, and dress-out days were recorded by the teacher. The results of this study suggested that having a choice indeed impacted the dependent variables of the study, which included perceived autonomy, perceived competence, motivation, and enjoyment. The quantitative data suggested that offering choices led to greater self-determination among the students. Self-determination index scores revealed significant main effect of condition $(F[2,109]=11.189, p<.0125)$. A significant main effect on condition was also evident on autonomy $(F[1.88,206.748]=9.763, p<.001)$ revealing a significant difference between baseline and non-choice and between choice and non-choice. 
Subsequent student focus group interviews suggested that students' choices must be relevant and meaningful and that offering only two choices was not sufficient.

How, Whipp, Dimmock, and Jackson (2013) investigated the impact of choice in high school PE and whether choice enhances autonomous motivation, perceived autonomy support, and actual PA levels. Students $(N=257)$ from eight high school PE classes were randomly assigned to a control group or an intervention group. Students in the intervention group were given certain parameters with regards to time, intensity, and type of activity, and tasked with developing a program within those parameters. The control group participated in a traditional teacher-led activity. The results of the study indicated that students within the control group experienced less positive perceptions of autonomy support. The findings indicate that offering choices in high school PE lessons may encourage perceptions of autonomy support and increase levels of in-class PA (How et al., 2013). Findings also suggest that allowing time in PE lessons for students to plan and execute their own activities could enhance their engagement in PA and perceptions about PE within the classroom, as well as enable them to make informed choices and sustain their PA levels outside of school.

Additional studies have explored the outcome of giving K-12 students the option to choose activities within the PE curriculum. Ward, Wilkinson, Graser, and Prusak (2008) sought to determine the effects of choice on student motivation and PA. Participants in the study were seventh and eighth grade girls $(N=122)$ from four classes, who were randomly assigned to either the choice or non-choice groups. Each group completed two different seven-day cardiovascular (CV) fitness units; in one they were given a choice of activity and in the other they completed predetermined activities. Motivation was measured using a 16-item, four factor abridged version of the Sport Motivation Scale (SMS). The four factors were amotivation, defined as the lack of 
motivation, external regulation, meaning behaving to attain a reward, identified regulation, operationalized as participating to achieve a desired outcome, and intrinsic motivation, viewed as participating for reasons within self (Deci \& Ryan, 1985). Additionally, the 14-item situational intrinsic motivation scale (SIMS) was used to measure situational motivation; self-determination index (SDI) scores were derived from this scale. The SIMS was administered twice, following each of the seven-day units. Finally, the Walk4Life LS 2015 pedometer (Walk4Life, Plainfield, IL) was used to measure step counts accumulated, as an indicator PA levels. Results of the SIMS indicated that there was a significant difference between choice and no choice groups $F$ $(1,112)=9.28, p<.003)$. Motivation scores increased when going from no choice in unit $1(M=$ $8.38, S D=6.37)$ to choice in unit $2(M=10.68, S D=6.73)$; and motivation scores decreased when going from choice in unit $1(M=8.94, S D=5.21)$ to no choice in unit $2(M=3.27, S D=$ 7.76). With regards to PA, there was no significant difference between groups. Group means were relatively similar in number of steps collected from pedometer data. The researchers attribute this to the fact that the study was conducted in a middle school PE class where students will typically participate in activities regardless of choice and no choice simply because that is what they were told to do.

Deci and Ryan (1985) hypothesized that everyone is, to some extent, autonomy-oriented, defined as the tendency for behavior to be initiated and regulated by events internal to one's sense of self. The center of this orientation is the experience of choice. Individuals who are autonomy-oriented will use available information to make choices and regulate themselves in pursuit of self-selected goals (Deci \& Ryan, 1985). According to Deci \& Ryan, the term "choice" is intended to be a motivational concept. 
With the decline in PA among young adults, it is imperative that we find motivating factors and strategies that will influence PA behaviors that carry over into subsequent adult lifestyle choices. The findings of these studies suggest that choices can have a positive and motivating impact on behavior, including PA.

\section{Motivation}

Motivation is thought to be a singular construct (Ryan \& Deci, 2000); however, there are many different factors that move an individual to act. Differing consequences and experiences influence multiple factors involved in motivation: desire, bribery, coercion, or personal commitment, among others. Ryan and Deci's (1985) Theory of Self-determination suggests that competence, autonomy, and relatedness are three primary psychological needs that drive human behavior. Competence is the need for being effective in one's interaction with the environment. Autonomy is the feeling of being free from pressure and having the possibility to make choices among several courses of action. Finally, relatedness refers to interpersonal attachments and bonds developed between individuals; relatedness is based on the need for contact with others (Guay, Vallerand, \& Blanchard, 2000).

Influences on motivation may be either intrinsic or extrinsic in nature. Amotivation is the absence of motivation for an activity and is at one extreme. Intrinsic motivation, on the other hand, is the motivation to do an activity for the simple fact that it provides pleasure and individuals are willing to engage in the activity for its own sake. Amotivation and intrinsic motivation fall at opposite ends of a continuum and levels of extrinsic motivation fall between these extremes (DeLong, 2006). Ryan and Deci (2000) suggest that intrinsic motivation has incredible positive potential for human nature. The nature of humans to seek new challenges, to go beyond one's capacity, to explore, and to learn are the phenomenon that is intrinsic 
motivation. Intrinsic motivation is the highest level of self-determination (DeLong, 2006).

Research suggests that there are strong links between intrinsic motivation and satisfaction in the need for autonomy and competence (Ryan \& Deci, 2000). Intrinsic motivation is enhanced when an individual feels autonomous and in control of his or her outcomes (Patall, Cooper, \& Robinson, 2008). Additionally, relatedness shows links to intrinsic motivation to an extent. We are all born with abundant intrinsic motivational tendencies; however, these tendencies require supportive conditions that elicit and sustain intrinsic motivation (Ryan \& Deci, 2000). Without support, intrinsic motivation is easily disrupted.

Cognitive evaluation theory (CET) (Deci \& Ryan, 1985) is a sub-theory of selfdetermination theory which explains variability in intrinsic motivation (Ryan \& Deci, 2000). Cognitive evaluation theory delves into the social and environmental factors that influence intrinsic motivation. According to CET, people must not only experience competence or efficacy, they must also experience their behavior as self-determined for intrinsic motivation to be in evidence (Ryan \& Deci, 2000). Cognitive Evaluation Theory only exists when experiences are novel and intrinsically interesting or appealing to the individual.

Self-determination theory not only considers intrinsic motivation, but extrinsic motivation as well. Extrinsic motivation refers to the performance of an activity in order to attain some separable outcome (Ryan \& Deci, 2000). Extrinsic motivation can include an individual doing PA for the simple reason that they will experience health benefits, as well as an athlete who performs certain physical activities in order to get more "playing time". Both experiences are extrinsically motivated, however, for different reasons and varying degrees of autonomy. Chaubal (2011) conducted a study on the effects of knowledge of exercise benefits on attitude, motivation, and exercise participation, and concluded that individuals who scored 
higher on a knowledge test also scored higher on the Exercise Motivational Inventory scale (EMI-2). It was concluded that knowledge of exercise benefits, which is considered an external motivator, contributed to motivation towards exercise.

External regulation, introjected regulation, identified regulation, and integrated regulation are four categories of extrinsic motivation. Extrinsic motivation that has less autonomy, is considered externally regulated, and is satisfying an external demand is considered external regulation (Ryan \& Deci, 2000). At this level of regulation, motivation is spurred solely by rewards or avoidance of punishment (Ryan \& Deci, 2000). A second form of extrinsic motivation, introjected motivation, involves behaviors that are reflective of ego, guilt, anxiety, or esteem. A third form of extrinsic motivation is regulation through identification, where individuals identify motivation and evaluate the value of a certain behavior. Identified regulation occurs when individuals freely choose to participate in an activity because they begin to value it and feel that it is important (Ryan \& Deci, 2000). This form of extrinsic motivation is more autonomous than the prior two forms. The most autonomous of the extrinsic types of motivation is integrated regulation. Integrated regulations are assimilated to the self (Ryan \& Deci, 2000). While this category of motivation is similar to intrinsic, it is still considered extrinsic because behaviors are performed for a separable outcome rather than for internal enjoyment.

A central distinction within self-determination theory is between controlled motivation and autonomous motivation (Ryan \& Deci, 2008). Controlled motivation is consistent with external regulation and introjected regulation. Controlled motivation gives individuals a sense of pressure to think, feel, or behave in a particular way. Autonomous motivation encompasses both intrinsic and types of extrinsic motivation that form identified and integrated regulation. When an individual is autonomously motivated, they experience a self-endorsement of their actions 
(Ryan \& Deci, 2008). Providing choice may be the most obvious way to support a person's experience of autonomy (Patall et al., 2008). Autonomous motivation leads to greater long-term persistence of behavior such as health- enhancing activities. In fact, both laboratory and field research suggest that choice has positive consequences across diverse circumstances, including educational, workplace, and health contexts (Patall et al., 2008).

Flink, Baggiano, and Barrett (1990) found that performance impairment was evident when children were taught by controlling strategies with no choice options, suggesting that development in classroom performance was flawed due to the controlling nature of the teaching strategy. The researchers surveyed 267 fourth- grade children on their motivational orientations within the classroom. Teachers were randomly assigned to one of two conditions: controlling and non-controlling strategies in the classroom. This study was conducted on elementary students in a classroom setting; however, it was constructed to explore the effects of controlling strategies on students' self-determination and performance. The similarity in teacher strategies and its impact on student performance gives rise to the inquiry into how teaching styles may impact other areas of learning such as in a PE setting.

Causality and aspirations of life goals. Within self-determination theory, there are orientations of causality and aspirations of life goals. Causality orientations refer to the way people orient to the environment with regards to initiation and regulation of behavior and the extent to which they are self-determined in general (Ryan \& Deci, 2008). The three orientations include: autonomous, controlled, and impersonal. Autonomous orientation has been positively related to psychological health and effective behavioral outcomes (Ryan \& Deci, 2008). Aspirations of life goals fall into two categories that include intrinsic aspirations and extrinsic aspirations (Kasser \& Ryan, 1996). Intrinsic aspirations include meaningful relationships, 
personal growth, and community contributions. Extrinsic aspirations are those related to wealth, fame, and attractiveness. Studies indicate that individuals with a greater sense of intrinsic goals are associated with greater health, well-being, and performance (Vansteenkiste, Simons, Lens, Sheldon, \& Deci, 2004).

There have been many studies on motivation towards PA. A study of children's motivation in physical education (Standage, Duda, \& Ntoumanis, 2003) collected data on 328 children attending two different secondary schools. Students completed a survey questionnaire assessing their perceptions of the PE class climate, autonomy, competence, relatedness, motivation, and leisure-time PA intentions. The climate measure determined the degree to which the students perceived the teacher and the class climate to be autonomous (origin) versus controlling (pawn). Motivation toward PE was assessed using an adapted version of the Situational Motivation Scale (SMS), a 28-item inventory subdivided into seven subscales that measure motivational regulations proposed by self-determination theory (Patall et al., 2008). The study found that perceptions of competence and relatedness were more predictive of selfdetermined motivation than autonomy. Additionally, perceptions of a mastery and origin climate are positively and moderately associated with perceptions of autonomy, relatedness, and competence. These findings suggest that PE teachers should seek to promote class structures that are autonomy-supportive and mastery-focused, which ultimately facilitates self-determined motivation (Standage et al., 2003). Teachers can provide learning environments that promote satisfaction through the need for autonomy, competence, and relatedness. One way to achieve such a learning environment is by using autonomy-supportive styles, which can include providing choice and encouraging experimentation and self-initiation. 
Kilpatrick, Herbert, and Bartholomew (2005) suggested that motivation to exercise for health-related benefits is extrinsically motivated and sport participation more intrinsically motivating. Participants included 233 college students enrolled in lower level health-content courses. A modified version of The Exercise Motivation Inventory (EMI-2) was used to measure motivation with regards to participation in sport activities and also health-enhancing PA. The EMI-2 consists of a 51-item questionnaire with 14 subscales that are reflective of different motivational reasons for engaging in PA. The wording for the EMI-2 was modified for two different questionnaires, one pertaining to sport and the other pertaining to exercise. With regards to exercise, respondents reported higher motivation for reasons of appearance $F(1,227)$ $=144.41, p<.001$, strength and endurance $F(1,225)=66.74, p<.001$, stress management $F(1$, $228)=13.72, p<.001$, weight management $F(1,228)=113.74, p<.001$, health pressure $F(1$, $231)=23.52, p<.001$, ill-health avoidance $F(1,231)=193.56, p<.001$, and positive health $F(1,231)=140.22, p<.001$. The largest effect size difference was found in ill-health avoidance, positive health, and appearance. With regards to sport, respondents rated affiliation $F(1,227)=231.65, p<.001$, challenge $F(1,224)=48.46, p<.001$, competition $F(1,227)=$ $150.80, p<.001$, enjoyment $F(1,229)=21.84, p<.001$, and social recognition $F(1,231)=$ $88.95, p<.001$ as higher motivators with the largest effect size difference found in affiliation and competition. These findings indicated that sport participation is more closely linked to intrinsic motives, whereas exercise is associated with primarily extrinsic motives.

The results of this study warrant future research and may impact the future of health enhancing PA interventions. Kilpatrick et al. (2005) suggested that some societal pressures and health fears could actually have a negative impact on extrinsic motivation toward health- 
enhancing PA participation. Their findings support further examination of motivational factors associated with other PA interventions.

Brunet and Sabiston (2011) explored motivation for PA across the adult lifespan. The purpose of the study was to examine the relationship among motivational regulations and PA. Participants in the study consisted of 571 adult men and women ages 18-64. The Leisure Time Exercise Questionnaire (LTEQ) was used to assess self-reported PA behavior. Participants were asked how often they participated in mild, moderate, and strenuous PA for more than 15 minutes in the last week. Additionally, participants were asked to report how often they engaged in regular activity that resulted in increased heartbeat and sweating during a typical week. They were asked to rate the level of activity based on a 3-point Likert scale ranging from (1) often to (3) never. The Behavioral Regulation in Exercise Questionnaire (Mullan, Markland, \& Ingledew, 1997) was used to assess motivation for PA. The BREQ includes 15 items measuring external regulation, identified regulation, and intrinsic motivation. The participants responded to the questions using a 5-point scale from (0) not true for me to (4) very true for me. Results from the study indicated high levels of identified regulation and low levels of external regulation. The findings suggest that regardless of age, individuals 18-64 years old report being motivated to engage in PA because it is congruent with their personal values, goals, needs, and/or because they find it inherently enjoyable. Middle-aged adults specifically reported lower levels of intrinsic motivation, introjected regulation and PA behavior than the younger adults. Brunet and Sabiston (2011) indicated that intrinsic motivation is a strong correlate of PA behavior and that future research in identifying the mechanisms underlying the differences among age groups is suggested. Additionally, autonomous motivation, which consists of intrinsic motivation and identified regulation, was a significant positive correlate, whereas external regulation was a 
significant negative correlate of self-reported PA behavior. According to Brunet and Sabiston (2011), these findings suggested that young adults' PA levels increase as their beliefs that PA is inherently pleasurable and the value and importance they place on it increases. Thus, PA interventions may benefit from promoting or maintaining autonomous regulations within youngadult populations.

Sibley, Hancock, \& Bergman (2013) conducted a study with 194 undergraduate college students enrolled in fitness-based PA class. This study examined relationships between exercise motives, exercise behavioral regulations, and physical fitness in college students (Sibley et al., 2013). The university required two semester hours of PA course work. Students self-selected into the activity classes used in the study. Behavioral regulation was measured using the BREQ-2, a 19-item questionnaire which is divided into 5 subscales designed to measure amotivation, external regulation, introjected regulation, identified regulation, and intrinsic regulation. The BREQ-2 is a modified version of the BREQ which includes amotivation. Other measures in the study included a revised version of the motive for PA measure (MPAM-R), the pacer test (aerobic fitness measure), and a bioelectrical impedance analyzer (body composition measure). The BREQ-2 regression model was found to significantly predict aerobic fitness, specifically intrinsic regulation predicted aerobic fitness with a significant value of $p<.001$. These findings suggested that those who are more intrinsically motivated to exercise scored higher on the aerobic fitness test. Additionally, the BREQ-2 regression model significantly predicted body composition with introjected regulation $(p<.001)$. Sibley et al. (2013) suggested that autonomous motivation leads to increased exercise behavior, improved exercise adherence, and greater self-reported PA. Moreover, these findings can be viewed as confirmation that more 
autonomous forms of motivation are more effective in promoting exercise adherence and ultimately affecting physical fitness (Sibley et al., 2013).

Motivation for PA is also being studied in the medical field. Fortier, Sweet, O'Sullivan, \& Williams (2007) investigated the use of PA counseling in a primary care intervention. The purpose of the study was to determine if participants in the experimental group would report higher levels of autonomy support, autonomous motivation, and perceived competence and if that would predict higher levels of PA. Participants $(N=120)$ were recruited from a primary care practice which included patients between the ages of 18-69 who reported less than 150 minutes of PA per week. Participants were randomly assigned to either the experimental or control condition. All participants experienced baseline PA counseling. The experimental group received additional intensive PA counseling. The Health Care Climate Questionnaire was used to measure autonomy support, the Treatment Self-Regulation Questionnaire was used to measure autonomous motivation, the Perceived Competence for Exercise Scale measured perceived competence, and the Godin Leisure Time Exercise Questionnaire was used to measure PA. Results indicated that participants in the experimental group reported significantly higher scores on autonomous motivation than those in the control group $F(1,117)=4.47, p<.05$. Additionally, participants in the experimental group reported higher levels of PA at the end of the study than those in the control group $F(1,117)=16.83, \mathrm{p}<.001$. Results indicate that intensive PA counseling led to greater autonomous motivation and PA. While this study took place in the healthcare setting, further research is warranted to determine intervention methods that can lead to improving autonomous motivation and PA.

Most researchers are in agreement that treatment environments affording autonomy and in addition, support confidence are likely to enhance adherence and health outcomes (Ryan, 
Patrick, Deci, \& Williams, 2008). Research investigating supportive conditions that increase motivation, specifically with regard to PA, is of vital importance. The decline of healthenhancing PA among young adults has far-reaching consequences for the future well-being of our population. Increasing motivation for PA becomes a critical topic, because of the differing learning approaches required for effective learning in varying age groups.

\section{Adult Learning}

Adults and children learn differently; adults approach learning with prior knowledge and a greater amount of life experiences when compared with children, and adult trait characteristics are not as capable of being produced as in children (Birzer, 2004). Andragogy by definition is the art and science of helping adults learn (Knowles, 1980). As far back as 1926, it was suggested that the best approach to adult education would be via the route of situations, not subjects (Lindeman, 1961). Subsequently, Lindeman (1961) concluded that, "too much of learning consists of vicarious substitution of someone else's experience and knowledge....whereas experience is the adult learner's living textbook" (p.7). In adult education the curriculum should be built around the student's needs and interests (Lindeman, 1961).

The andragogical model (Knowles, 2011) is based on assumptions regarding adult learners. The andragogical model proposes that adults come to the table with the need to know, their self-concept, their own experiences, a readiness to learn, an orientation to learning, and motivation (Knowles, Holton, \& Swanson, 2011). These core principles of adult learning are believed to enable those planning and conducting adult learning to design more effective learning processes (Holton, Swanson, \& Naquin, 2001). In general, adult educators find these assumptions vis-à-vis adult learners beneficial in developing the learning process to be more effective with adults (Holton et al., 2001). 
The andragogical model is rooted in adult learning theory and suggests that adults need to know why, what, and how they will learn. The model takes into consideration, the self-concept of the learner, prior experiences of the learner, readiness to learn, the orientation of the learner, and motivation to learn (Knowles, 2011). The adult learner has a need for autonomy and selfdirectedness in their learning experiences which contributes to motivation in addition to personal payoff. Andragogy is a transactional model of adult learning designed to surpass specific applications and situations. Knowles et al. (2011) suggest that the humanistic perspective, one of the two roots of the model (Holton et al., 2001), is primarily concerned with self-actualization of the individual and the other root, a pragmatic perspective, values knowledge gained from experience rather than formal authority. Knowles (1977) states, "a true andragogue has a built-in sense of obligation to do everything one can to help that person move from dependency toward increasing self-directedness" (p. 206). Moreover, the instructional approach is to ultimately facilitate the situation so that the learner becomes self-directed in his/her own learning.

Andragogy can be imbedded within many different sets of goals and purposes that may affect the learning process differently (Knowles et al., 2011). Some colleges and universities insert andragogical approaches into the curriculum. Tannehill (2009) explored how postsecondary institutions educate adult learners, specifically addressing andragogy and its application in post-secondary institutions. Tannehill (2009) sought to discover whether institutions utilize the principles of andragogy in educating adult learners. College administrators, recruited from the University Continuing Education Association, completed a total of 85 surveys. Participants were employed by institutions who were members of this organization. Survey questions consisted of, but were not limited to, questions pertaining to whether institution faculty offered a variety of instructional methods to deliver information. 
Seventy-six percent of institutions reported that they indeed did offer a variety of instructional methods such as project based learning, collaborative learning, or self-directed learning.. Additionally, 73 percent of the institutions reported that the learner was active in the learning process and 71 percent reported having a mutually respectful relationship with the learner. Tannehill (2009) reported that overall, baccalaureate institutions reported utilizing principles of andragogy in higher percentages than other institutions, while community colleges were among the institutions offering the best programs based on andragogical principles for non-traditional students.

Birzer (2004) discussed the implementation of the andragogical model in a criminal justice program. He specifically incorporated Knowles' principles of andragogical practice such as creative appropriate learning environments, including the learner in curricular planning, and methodologies. Additionally, learners were involved in establishing learning objectives, available resources, learning needs. The facilitators played an active role in helping the learner implement his/her learning plan as well as involve them in the evaluation process. Birzer (2004) concluded that integrating the andragogical principles, as laid out by Knowles, led to the desired end result of learning, the absorption of knowledge of general problem solving strategies, critical thinking, and reflective learning.

When using an andragogical approach, teachers and learners work together to design instructional content and methods to suit the learners' needs (Chan, 2010). Hansman (2001) suggests that real-world contexts where there are social relationships and tools make the best learning environments. Experiential learning emphasizes doing the task in order to learn it, and this "doing" may include self-directed learning activities (Hansman 2001). For example, in a PE setting, actual participation in PA could result in experiential learning. It is one thing to explain 
the principles of training, but to actually apply the information in context allows an individual to physically experience what is being taught. The experience of specifically lifting a weight or experiencing an increased heart rate in a cardio-fitness routine is where the learning takes place.

When the instructor uses the existing knowledge, experience, and motivation of learners to shape the learning experience, his/her role shifts from traditional teacher to a facilitator of learning (Knowles et al., 2011). Furtak and Kunter (2012) added that teachers become providers of guidance and scaffolding for student learning. Students are then seen as autonomous participants, actively engaged and responsible for the learning process. Students are awarded more autonomy over their own learning process, which may help them to engage in meaningful learning activities and ultimately achieve favorable development and learning outcomes (Furtak \& Kunter, 2012). The concept of autonomy that is central within self-determination theory has long been recognized as a fundamental factor in the promotion of optimal motivation.

Additionally, autonomy and the need to be more self-directed in the learning process are central components in adult learning theory. Autonomous-supportive teaching strategies align with adult learning approaches, suggesting that adult learners universally want to have control over their learning process (Knowles et al., 2011). Additionally, autonomy-supportive teachers facilitate the congruence between students' self-determined inner motives with their classroom activities by creating opportunities for these inner motives to guide their learning and activity (Reeve, Jang, Carrell, Jeon, \& Barch, 2004).

Reeve et al. (2004) investigated (a whether or not experienced high school teachers could capitalize on a brief workshop experience with follow-up independent study to expand their existing motivating styles and (b) whether students' engagement would be sensitive to such an experimentally-induced change in their teacher's motivating style. Teachers $(N=20)$ were 
recruited from two Midwest high schools for a 10-week study. The teachers were randomly assigned to either an experimental $(n=10)$ or delayed-treatment control group $(n=10)$. The experimental group received a 1-hour informational session on how to be autonomy supportive; they also participated in an independent study on autonomy support during weeks 3-5. The delayed-treatment control group received the 1-hour session and participated in the independent study during week 6 . Blind observations were conducted in the classroom during week 2, 5, and 10 by trained raters. The trained observers rated teacher autonomy support and two aspects of student engagement (task involvement and influence attempts). Teacher autonomy support was measured using an observer-rating sheet that consisted of four autonomy supportive behaviors. Engagement was measured using a 5-item rating scale. Results for Hypothesis 1 indicated that teachers in the experimental group used significantly $(p<.01)$ more autonomy supportive behavior than the control group. Results of Hypothesis 2 indicated that increased autonomy support had a significant $(p<.01)$ effect on both measures of engagement. Findings indicated that veteran teachers can become more autonomy supportive in a way that produces an increase in student engagement.

Hagger, Culverhouse, Chatzisarantis, and Biddle (2003) investigated students' perceived autonomy support in high school PE, and sought to explain how young people's perceptions of an autonomy supportive environment affected their motives in a PE context and their PA motives, intentions, and behavior in a leisure-time PA context. In other words, if an individual experiences an increased perception of autonomy support which affects their motives, intentions, and behavior in one context (i.e., PE), will those same motives, intentions, and behaviors transfer to another context (i.e., leisure time activities)? 
In the Hagger et al. (2003) study, participants $(N=295)$ were recruited from 8th, 9th, and 10th grade homeroom classes. Perceived autonomy support, which is the degree to which individuals perceive others in positions of authority to be autonomy supportive (Deci \& Ryan, 1987), was measured using a 6-item modified version of the Sport Climate Questionnaire. Selfreported PA behavior and past behavior were measured using two different questionnaires. Past behavior was measured by one item on a 6-point scale from 1 (not at all) to 6 (most of the days per week). PA was measured using the Leisure Time Exercise questionnaire (Godin, 2011).

Findings suggest that there was a small impact of perceived autonomy support on leisure time PA behavior and a significant total effect. The main findings indicate that perceived autonomy support predicts the relative degree of autonomy of the behavior perceived by the individual in a PE context, which affects leisure-time PA intentions and behavior (Hagger et al., 2003). In other words, when an individual's perceived autonomy support increases, then their perceived ability to be autonomous in a certain behavior increases. This ultimately has a positive effect on leisure-time activity intentions and behavior.

Many adult educators suggest the goal of all learning should be to increase personal autonomy (Holton et al., 2001; Knowles 1977), meaning to take control of the goals and purposes of learning and assume ownership of the learning process (Knowles et al., 2011). Knowles' Andragogical Model suggests that the self-concept of the adult learner drives the need for autonomy. Previous studies (Hagger et al., 2003; Furtak \& Kunter, 2012) suggest that autonomy positively correlates to the learning process and motivation, but these studies have focused on high school students as subjects, whereas the Andragogical Model specifically addresses the art and science of helping adults learn. 
As the field of PE has developed, motivation and choice (autonomy) have become topics of interest in efforts to promote PA that endures beyond childhood, beyond a PE class, and into young adulthood. Corbin and Cardinal (2008) suggest that more research is needed in order to fully understand the most effective ways to teach college and university students in conceptually based college health and wellness courses. To date, there has been no research on andragogical teaching strategies applied in the more adult college physical education setting. Because college campuses are said to be an optimal place to impact PA patterns in young adults (Leslie et al. 2001) and PA patterns students develop during college years have a long-term impact throughout adulthood (Keating et al. 2005); this research has the potential to find new ways to improve the overall health and wellness as well as increase or maintain appropriate PA levels in young adults. 


\section{References}

Adams, T., \& Brynteson, P. (1995). The effects of two types of required physical education. Physical Educator, 52(4), 203-211.

Alemada, A. (2009). Effect of a 15-week wellness course on health indicators and six areas of wellness in college students, (Doctoral dissertation). retrieved from ProQuest. (3544507)

American College Health Association. (2012, June). Healthy Campus 2020. Retrieved March 2014, from http://www.acha.org/HealthyCampus/index.cfm.

Birzer, M. (2004). Andragogy: Student centered classrooms in criminal justice programs. Journal of Criminal Justice Education. 15(2), 393-411.

Brunet, J., \& Sabiston, C. (2011). Exploring motivation for physical activity across a lifespan. Psychology of Sport and Exercise, 12, 99-105. doi:10.1016/j.psychsport.2010.09.006

Campbell, A. (2012). Impact of choice on student motivation, autonomy, competence, and enjoyment in high school physical education. (Doctoral dissertation). Retrieved from Proquest. (3528772).

Centers for Disease Control and Prevention. (2014) Physical Activity. Retrieved from http://www.cdc.gov/physicalactivity/index.html.

Chan, S. (2010). Applications of andragogy in multi-disciplined teaching and learning. Journal of Adult Education. 39(2), 25-35.

Chaubal, S. (2011). Effect of knowledge of exercise benefits on attitude, motivation, and exercise participation, (Master's Thesis). State University of New York, Cortland.

Corbin, C., \& Cardinal, B. (2008). Conceptual physical education: The anatomy of an innovation, Quest, 60(4), 467-487, doi: 10.1080/00336297.2008.10483593. 
Deci, E. \& Ryan, R. (1985). Intrinsic motivation and self-determination in human behavior. New York, Plenum Press.

DeLong, L. (2006). College students' motivation for physical activity. (Doctoral dissertation).

Flink, C., Baggiano, A., and Barrett, M. (1990). Controlling teaching strategies: Undermining children's self-determination and performance. Journal of Personality and Social Psychology. 59(5), 916-924.

Fortier, M., Sweet, S., O’Sullivan, T., and Williams, G. (2007). A self-determination process model of physical activity adoption in the context of a randomized controlled trial. Psychology of Sport and Exercise, 8, 741-757. doi:10.1016/j.psychsport.2006.10.006

Furtak, E. \& Kunter, M. (2012). Effects of autonomy-supportive teaching on student learning and motivation. The Journal of Experimental Education, 80(3), 284-316. doi: 10.1080/00220973.2011.573019.

Godin, G. (2011). The Godin-Shephard leisure-time in exercise questionnaire. Health and Fitness Journal of Cananda, 4(1), 1-7.

Guay, F., Vallerand, R., \& Blanchard, C. (2000). On the assessment of situational intrinsic and extrinsic motivation: The situational motivation scale (SIMS). Motivation \& Emotion. 24(3). 175-213.

Hagger, M., Chatzisarantis, N., Culverhouse, T., \& Biddle, S. (2003). The process by which perceived autonomy support in physical education promotes leisure-time physical activity intentions and behavior: A trans-contextual model. Journal of Educational Psychology, 95(4), 784-795. doi: 10.1037/0022-0663.95.4.784.

Hansman, C. (2001). Context-based learning. New Directions for Adult and Continuing Education. 89, 43-51. 
Hasstie, P. (1996). Teaching Sport within Physical Education. In S.J. Silverman, \& C.D. Ennis (Eds) Student learning in physical education: applying research to enhance instruction (pp. 227-238). Champaign, IL: Human Kinetics.

Hellison, D. (1996). Teaching Personal and Social Responsibility in Physical Education. . In S.J. Silverman \& C.D. Ennis (Eds) Student learning in physical education: applying research to enhance instruction (pp. 241-254). Champaign, Ill.: Human Kinetics.

Hensley, L. (2000). Current status of basic instruction programs in physical education at American colleges and universities. Journal of Physical Education, Recreation \& Dance. 71(9). 30-36. doi: 10.1080/07303084.2000.10605719.

Hodges-Kulinna, P., Warfield, W.W., Jonaitis, S., Dean, M., \& Corbin, C. (2009). The progression and characteristics of conceptually based fitness/wellness courses at American universities and colleges. Journal of American College Health, 58(2), 127-131.

Holton, E., Swanson, R. \& Naquin, S. (2001). Andragogy in practice: Clarifying the andragogical model of adult learning. Performance Improvement Quarterly, 14(1) 118143.

How, Y., Whipp, P., Dimmock, J., \& Jackson, P. (2013). The effects of choice on autonomous motivation, perceived autonomy support and physical activity levels in high school physical education. Journal of Teaching in Physical Education, 32, 131-148.

Kasser, T., \& Ryan, R. (1996). Further examining the American dream: Differential correlates of intrinsic and extrinsic goals. Personality and Social Psychology Bulletin, 22, 280-287.

Keating, X., Guan, J., Pinero, J., \& Bridges, D. (2005). A meta-analysis of college students' physical activity behaviors. Journal of American College Health, 54(2), 116-125. 
Kilpatrick, M., Hebert, E., \& Bartholomew, J. (2005). College students' motivation for physical activity: Differentiating Men's and Women's motives for sport participation and exercise. Journal of American College Health, 54(2), 87-94.

Knowles, M. (1977). Adult learning processes: Pedagogy and andragogy. Religious Education. 72(2), 202-210.

Knowles, M. (1980). The modern practice of adult education: from pedagogy to andragogy. Chicago Ill: Association Press.

Knowles, M. (2011). The adult learner: The definitive classic in adult education and human resource development, (7th ed.). Amsterdam, The Netherlands: Elsevier.

Knowles, M., Holton, E., \& Swanson, R. (2011). The adult learner: the definitive classic in adult education and human resource development ( $7^{\text {th }}$ ed.) Oxford, UK: Elservier.

Kulinna, P. (2008). Models for curriculum and pedagogy in elementary school physical education. The Elementary School Journal, 108(3).

Hodges-Kulinna, P., Warfield, W.W., Jonaitis, S., Dean, M., \& Corbin, C. (2009). The progression and characteristics of conceptually based fitness/wellness courses at American universities and colleges. Journal of American College Health, 58(2), 127-131.

LaFountaine, J., Neisen, M., \& Parsons, R. (2006). Wellness factors in first year college students. American Journal of Health Studies, 21(4), 214-218.

Layne, T. \& Piipari, S. (2015). Effects of the sport education model on university students' game performance and content knowledge. Journal of Sports Research, 2(2), 24-36.

Leslie, E., Sparling, P., \& Owen N. (2001). University campus settings and the promotion of physical activity in young adults: lessons from research in Australia and the USA. Health Education, 101(3), 116-125. 
Lindeman, E. (1961). The meaning of adult education. New York New: York Republic Inc.

Lumpkin, A. (1993). Basic instruction programs: A brief history. Journal of physical education recreation and dance, 64, 32-36.

Medero, M. (2012). The effectiveness of a conceptually-based health and wellness course in developing health related factors, exercise self-efficacy and knowledge of health issues and exercise performance among diverse college students. (Doctoral dissertation).

Mullen, E., Markland, D., \& Ingledew, D. (1997). A graded conceptualization of selfdetermination in the regulation of exercise behavior: Development of a measure using confirmatory factor analytic procedures. Personal Individual Differences, 23(5), 745-752.

National Association for Sport and Physical Education \& American Heart Association. (2012). 2012 Shape of the Nation Report: Status of Physical Education in the USA. Reston, VA: American Alliance for Health, Physical Education, Recreation and Dance.

Patall, E., Cooper, H., \& Robinson, J. (2008). The effects of choice on intrinsic motivation and related outcomes: A meta-analysis of research findings. Psychological Bulletin, 134(2), 270-300.

Pearman, S. (1995). The impact of a required college health and physical education course on the health status of alumni. Journal of American College Health, 46(2), 77-85.

Placek, J. (1996). Interdisciplinary Curriculum in Physical Education: Possibilities and Problems. In S.J. Silverman \& C.D. Ennis (Eds) Student learning in physical education: applying research to enhance instruction (pp. 255-271). Champaign, Ill.: Human Kinetics.

Reeve, J., Jang, H., Carrell, D., Jeon, S., \& Barch, J. (2004). Enhancing students' engagement by increasing teachers' autonomy support. Motivation and Emotion, 28(2), 147-169. 
Ryan, R. \& Deci, E. (2000). Self-determination theory and the facilitation of intrinsic motivation, social development, and well-being. American Psychologist, 55(1), 68-78.

Ryan, R. \& Deci, E. (2008). Self-determination theory: A macrotheory of human motivation, development, and health. Canadian Psychology, 49(3), 182-185.

Ryan, R., Patrick, H., Deci, E., \& Williams, G. (2008). Facilitating health behavior change and its maitanance: Interventions based on self-determination theory. European Health Psychology Society, 10(1), 1-23.

Sallis, J. (2000). Age-related decline in physical activity: a synthesis of human and animal studies. Medicine and Science in Sports and Exercise, 1598-1600. doi 01959131/00/3209-1598/0.

Sallis, J., Mackenzie, T., Alcaraz, J., Kolody, B., Faucette, N., Hovell, M. (1997). The effects of a 2-year physical education program (SPARK) on physical activity and fitness in elementary school students. American Journal of Public Health, 87(8), 1328-1334.

Sibley, B., Hancock, L., and Bergman, S. (2013). University students' behavioral regulation, motives, and physical fitness. Perceptual and Motor Skills: Exercise and Sport. 116(1), 322-339.

Siedentop, D. (1994). Sport education: Quality PE through positive sport experiences. Champaign, IL: Human Kinetics.

Siedentop, D. (1998). What is sport education and how does it work? Journal of Physical Education, Recreation, and Dance, 69(4), 18-20.

Sparling, P. (2003). College physical education: An unrecognized agent of change in combating inactivity-related disease. Perspectives in Biology and Medicine. 46(4). 579-587. 
Solomon, J. \& Murata, N. (2008). Physical education and language arts: An interdisciplinary teaching approach. Strategies: A Journal for Physical and Sport Educators, 21(6), 19-23.

Standage, M., Duda, J., \& Ntoumanis, N. (2003) A model of contextual motivation in physical education: Using constructs from self-determination and achievement goal theories to predict physical activity intentions. Journal of Educational Psychology, 95(1), 97-110.

Tannehill, D. (2009). Andragogy: How do post-secondary institutions educate and service adult learners? (Doctoral dissertation).

United States Department of Health and Human Services. (2001). The Surgeon General's call to action to prevent and decrease overweight and obesity. [Rockville, MD]: U.S. Department of Health and Human Services, Public Health Services, Office of the Surgeon General; Available from: U.S. GPO, Washington.

Vansteenkiste, M., Simons, J., Lens, W., Sheldon, K., \& Deci, E. (2004). Movtivation learning, performance, and persistence: The synergistic effects of intrinsic goal contents and autonomy-supportive context. Journal of Personality and Psychology. 87(2), 246-260.

Ward, J., Wilkinson, C, Graser, S., \& Prusak, K. (2008). Effects of choice on student motivation and physical activity behavior in physical education. Journal of Teaching in Physical Education, 27, 385-398. 


\section{Appendix B}

\section{West Virginia University Informed Consent Form}

You are being invited to participate in a research study about motivation towards physical activity. This study is being conducted by Julia Tracy MS, from the College of Physical Activity and Sport Sciences at West Virginia University. The purpose of the study is to investigate how time spent in a conceptually-based health and wellness class with choice will impact exercise motivation and physical activity behavior. An improved understanding of college students' motives for engaging in physical activity would assist in the development of tailored physical activity interventions. Understanding motivation and how to increase an individual's motivation towards regular physical activity is critical for successful college health and wellness courses.

There are no known risks associated with your participation in this research study. There are no costs to you for participating in the study. The semi-structured interview will take 30-50 minutes of your time. There were 2 participants in this portion of the study and you were asked questions pertaining to your experience as an instructor in the study. You were asked to give your perception of the impact of your teaching style on motivation towards physical activity. These questions will help the researcher to better understand student motivation in an activity setting. The information collected may not directly benefit you as an instructor but will provide information on general benefits for the tailoring of future physical activity programs.

The semi-structured interview were audio-recorded in order to accurately capture what is said. All information were kept confidential and voice data were stored on a password protected file. If you participate in the study, you may request that the recording be paused at any time. You may choose how much or how little you want to speak during the session and are free to skip any questions asked. You may also choose to leave the session at any time.

Anonymous data from this study were analyzed by the primary researcher and no individual participant were identified or linked to the results. Audio data were kept locked up and were destroyed by May 31, 2015.

1) Participation is completely voluntary,

2) Refusal to participate will not involve any penalty or loss of benefits to which you are otherwise entitled.

3) You may discontinue participation at any time without penalty or loss of benefits to which you are otherwise entitled.

For answers to pertinent questions about the research and research participants' rights, and whom to contact in the event of a research related injury to the participant, please contact

Dr. Larry Daily @ 304-876-5297, IRB Chair at SU, ldaily@ shepherd.edu.

Julia Tracy, jtracy@shepherd.edu or 540-336-1223.

ANY QUESTIONS REGARDING YOUR RIGHTS AS A RESEARCH PARTICIPANT

MAY BE ADDRESSED TO THE SHEPHERD UNIVERSITY INSTITUTIONAL REVIEW

BOARD (Larry Daily, IRB Chair, 304.876.5297). ALL RESEARCH PROJECTS THAT ARE

CARRIED OUT BY INVESTIGATORS AT SHEPHERD UNIVERSITY ARE GOVERNED

BY THE REQUIREMENTS OF THE UNIVERSITY AND THE FEDERAL

GOVERNMENT.

If you agree to participate, please sign below and return the form to the researcher.

Name:

Signature:

Date:

1




\section{Appendix C \\ West Virginia University Informed Consent Form}

You are being invited to participate in a research study about motivation towards physical activity. This study is being conducted by Julia Tracy MS, from the College of Physical Activity and Sport Sciences at West Virginia University. The purpose of this study is to determine the impact of choice in a conceptuallybased college health and wellness course (Fitness for Life) on exercise motivation and physical activity. An improved understanding of college students' motives for engaging in physical activity would assist in the development of tailored physical activity interventions. Understanding motivation and how to increase an individual's motivation towards regular physical activity is critical for successful college health and wellness courses.

You will complete a demographics survey as well as two questionnaires over three time points that measure motivation and leisure time in physical activity.

There are no known risks associated with your participation in this research study. There are no costs to you for participating in the study. The questionnaire will take about 15 minutes to complete. There are approximately 80-100 participants in the study. The information collected may not benefit you directly, but the information learned in this study will provide more general benefits for the tailoring of future physical activity programs.

Participation in the survey is anonymous. Please do not write your name on the questionnaire, envelop or anywhere else except in the bottom of this consent form that you will hand in separately from the questionnaire. Individuals from the Institutional Review Board may inspect these records. Should the data be published, no individual information were disclosed. Please observe the following regarding the survey:

1) Participation is completely voluntary,

2) Refusal to participate will not involve any penalty or loss of benefits to which you are otherwise entitled.

3) You may discontinue participation at any time without penalty or loss of benefits to which you are otherwise entitled.

For answers to pertinent questions about the research and research participants' rights, and whom to contact in the event of a research related injury to the participant, please contact

Dr. Larry Daily @ 304-876-5297, IRB Chair at SU, 1daily@ shepherd.edu.

Julia Tracy, Primary researcher @ jtracy@ shepherd.edu or 540-336-1223.

ANY QUESTIONS REGARDING YOUR RIGHTS AS A RESEARCH PARTICIPANT

MAY BE ADDRESSED TO THE SHEPHERD UNIVERSITY INSTITUTIONAL REVIEW

BOARD (Larry Daily, IRB Chair, 304-876-5297). ALL RESEARCH PROJECTS THAT ARE

CARRIED OUT BY INVESTIGATORS AT SHEPHERD UNIVERSITY ARE GOVERNED

BY THE REQUIREMENTS OF THE UNIVERSITY AND THE FEDERAL

GOVERNMENT.

If you agree to participate, please sign below and return.

Name:

Signature:

DATE: 


\section{Appendix D}

\section{Student Demographic Survey}

Responses to the following questions are completely anonymous and were used for research purposes only. Thank you for your cooperation!

Please check the appropriate box:

- Male $\square$ Female

Age:

What year are you in college?

- Freshman $\square$ Sophomore

- Junior $\square$ Senior

Do you commute to school?

- Yes $\square$ No

What is your approximate GPA?
- 2.0 or below
2.1-2.5
2.6-3.0
$3.1-3.5$
3.6 or above

Are you a student athlete?

- Yes $\square$ No

How much physical activity do you participate in during a typical week?

- $\quad$ Less than 150 minutes (2.5 hours) per week

- Approximately 150 minutes (2.5 hours) per week

- More than 150 minutes (2.5 hours) per week

What reason best describes why you registered for this particular section of GSPE-210?

- Convenience in my schedule

- This was the only section available

- I wanted this specific instructor based on his or her reputation

- I randomly picked this section

- Other: 


\section{Appendix E}

\section{Behavloral Regulation in Exercise Questionnaire (BREQ-2)}

The creators of the BREQ-2 are interested in the reasons underlying people's decisions to engage, or not engage in physical exercise. Using the scale below, please indicale to what extent each of the following ilems true for you. Please note that there are no right or wrong answers and no trick questions. We simply want to know how you per sonally feel about exercise. Your responses will be held in confidence and only used for research purposes.

1. I exercise because other people say I should

Not true

For me

2. T feel guilty when $T$ don' $T$ exercise

3. I value the benefits of exercise

4. I exercise because it is fin

5. I don't see why I should have to exercise

6. I take part in exercise because my friends' family'partner say I should

7. I feel ashamed when I miss an exercise session

8. It's important to the to exercise regularly

9. I can't see why I should bother exercising

10. I enjoy my exercise sessions

11. I exercise because others will not be pleased with me if I don't

12. 1 don't see the point in exercising

13. I feel like a failure when I haven't exercised in a while

14. I think it is important to make the effort to exercise regularly

15. I find exercise a pleasurable activity

16. I feel under pressure from my friends/family to exercise

17. I get restless if I don't exercise regularly

18. I get pleasure and satisfaction from participating ln exercise

19. I think exercising is a waste of time
Sometimes

true for me

Very true

for me

0

0

()

0

0

0

0

0

0

()

0

0

0

1

0

()

0

0

)

1 1

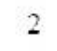

2

2

2

2

2

2

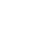

2

2

3

3

3

3

4

4

4

4

4

4

4 


\section{Appendix F}

\section{Student Generated Identification Code (SGIC)}

The following questions will generate a specific code on each questionnaire. This code will ensure your anonymity and confidentiality. These questions are personally relevant however cannot be specifically linked to your identity. The generated code will allow the researcher to link your surveys over three time-points throughout the semester while maintaining your anonymity. It is extremely important that you answer all four questions.

1. What are the last 2 digits of your Shepherd University student ID number?

2. What is the first letter of your mother's first name?

3. What are the last 2 digits in your personal cell phone number?

(If you do not own a cell phone, please write 00)

4. What is the first letter of the high school you graduated from?

(If you were home-schooled, please write $\mathbf{H}$ )

(If you earned a GED, please write $\mathbf{G}$ )

\section{The Godin-Shephard Leisure-Time Physical Activity Questionnaire}

During a typical 7 day period (a week), how many times on average do you do the following kinds of exercise for more than 15 minutes during your free time? (Write on each line the appropriate number).

\begin{tabular}{|l|l|}
\hline & Times per Week \\
\hline $\begin{array}{l}\text { Strenuous Exercise-Heart beats rapidly } \\
\text { (e.g. Running, jogging, hockey, football, } \\
\text { soccer, basketball etc.) }\end{array}$ & \\
\hline $\begin{array}{l}\text { Moderate Exercise-Not exhausting } \\
\text { (e.g. Fast walking, tennis, easy swimming, easy } \\
\text { bicycling etc.) }\end{array}$ & \\
\hline $\begin{array}{l}\text { Mild Exercise-minimal effort } \\
\text { (e.g. Yoga, golf without using a cart, easy } \\
\text { walking etc.) }\end{array}$ & \\
\end{tabular}




\section{Appendix G}

\section{Open-Ended Questions}

1) Did you find the Fitness for Life class to be motivating towards physical activity? If so, why? If not, Why?

2) Has your level of physical activity changed due to participation in Fitness for Life? Please explain why or why not.

3) What did you enjoy most about having a choice of activities/no choice of activities in your course? Please explain your answer.

4) What did you enjoy least about having a choice of activities/ no choice of activities in your course? Please explain your answer. 


\section{Appendix $\mathrm{H}$}

\section{Semi-structured Interview Script}

1) What activities do think students enjoyed most in your classes?

2) What did you think about choice or non-choice and their impact?

3) Do you feel there are barriers or challenges associated with choice and or non-choice?

4) What do you feel are the strengths of choice or non-choice in this type of setting?

5) Do you feel any students were more motivated or engaged because they did or did not have choice of activities? Were students any less motivated or engaged?

6) What do you think students liked best about having a choice/no choice?

a. Please give an example.

7) What do you think students liked least about having a choice/no choice and why?

a. Please give an example. 


\section{Appendix I}

\section{Fidelity Checklist}

Choice:

- The instructor is using an autonomous style of teaching to facilitate physical activity; the instructor has provided the students with guidelines for activity but has not prescribed a specific activity.

- Students are engaged in autonomous forms of physical activity of their choice. For example, students are engaging in activities in which they had free choice and input in the activity selection.

- Instructors provide input and feedback to students, but the main decision making of choice of activity rests with the student

\section{Non Choice:}

- The instructor is using a controlled style of teaching to lead students in physical activity. Students are following the instructor's directions and are engaged in activities led or directed by the instructor, (i.e. students are playing team handball as directed by the instructor)

- Students do not have a choice of the main activity for the day.

- Students are engaged in a group activity, of which the instructor is the lead, and are following the instructions from the instructor. 
Appendix $\mathbf{J}$

\section{Physical Activity Day-Choice Workout Template Cardio/Flexibility}

1. Briefly describe below what your warm-up activity were. Keep in mind that your warmup should be 5-10 minutes of low intensity activity.

2. Please fill in the chart below indicating the intensity, time, and type of activity you will engage in for your conditioning phase. Conditioning phase must be 20-30 minutes depending on intensity level.

\begin{tabular}{|l|l|}
\hline $\begin{array}{l}\text { Intensity } \\
\text { (HR range) }\end{array}$ & \\
\hline Time & \\
\hline Type & \\
\hline
\end{tabular}

3. Please indicate below what your cool-down activities were. Keep in mind that your cooldown is designed to slow your heart-rate to a more normal level. 


\section{Physical Activity Day Workout Template Muscle Fitness}

1. Briefly describe below what your warm-up activity were. Keep in mind that your warmup should be 5-10 minutes of low intensity activity.

2. Please fill in the chart below indicating the exercise, weight, sets, and reps of activity you will engage in for your conditioning phase.

\begin{tabular}{|l|l|l|l|}
\hline Exercise/description & Weight & Sets & Reps \\
\hline & & & \\
\hline & & & \\
\hline & & & \\
\hline & & & \\
\hline & & & \\
\hline & & & \\
\hline & & & \\
\hline & & & \\
\hline & & & \\
\hline & & & \\
\hline & & & \\
\hline
\end{tabular}

3. Please indicate below what your cool-down activity were. Keep in mind that your cooldown is designed to slow your heart-rate to a more normal level. 


\section{Appendix K}

Physical Activity Day Non-Choice (to be completed by the course instructor)

Week/Date:

Instructor name:

Directions: Please fill out the template below. Indicate what activity your class engaged in during the activity day.

1. Warm-up-

2. Conditioning phase/ game activity-

3. Cool-down/closing activity- 


\title{
Appendix L
}

\author{
Cover Letter Student
}

\section{Dear Participant}

The purpose of this study is to determine the impact of choice in a conceptually-based college health and wellness course (Fitness for Life) on exercise motivation and physical activity. An improved understanding of college students' motives for engaging in physical activity would assist in the development of tailored physical activity interventions. Understanding motivation and how to increase an individual's motivation towards regular physical activity is critical for successful college health and wellness courses.

This study has been reviewed and acknowledged by Shepherd University IRB. This project is being completed for partial fulfillment of requirements for a doctoral dissertation at WVU.

Students' statements were anonymous and confidential. The following procedures were followed to ensure confidentiality:

Students were given the questionnaire handout with an empty envelope. The instructor will give the questionnaire to those students who have signed and handed in the informed consent form. Students were informed that the Informed Consent forms were held until after grades have been posted. Students will put the completed questionnaire in the envelope and place it in a box upon leaving the classroom.

Students may omit any question they do not wish to answer, they may drop out at any time, participation in voluntary, and grades will not be affected based on participation.

Thank you for your participation in this study

Julia F. Tracy 


\section{Appendix M}

\section{Cover Letter Instructor}

\section{Dear Participant}

The purpose of this study is to determine the impact of choice in a conceptually-based college health and wellness course (Fitness for Life) on exercise motivation and physical activity. An improved understanding of college students' motives for engaging in physical activity would assist in the development of tailored physical activity interventions. Understanding motivation and how to increase an individual's motivation towards regular physical activity is critical for successful college health and wellness courses.

This study has been reviewed and acknowledged by Shepherd University IRB. This project is being completed for partial fulfillment of requirements for a doctoral dissertation at WVU.

Instructors' statements were anonymous and confidential. The following procedures were followed to ensure confidentiality:

There are no known risks associated with your participation in this research study. There are no costs to you for participating in the study. The semi-structured interview will take 20-30 minutes of your time. You were asked questions pertaining to your experience as an instructor in the study. The semi-structured interviews were audio-recorded in order to accurately capture what is said. All information were kept confidential and voice data were stored on a password protected file. If you participate in the study, you may request that the recording be paused at any time. You may choose how much or how little you want to speak during the session and are free to skip any questions asked. You may also choose to end the interview at any time.

Anonymous data from this study were analyzed by the primary researcher and no individual participant were identified or linked to the results. Audio data were kept locked up and were destroyed by May 31, 2015.

Thank you for your participation in this study

Julia F. Tracy 
